\title{
Metal species involved in long distance metal transport in plants
}

\author{
Ana Álvarez-Fernández, Pablo Díaz-Benito, Anunciación Abadía , Ana-Flor López-Millán and \\ Javier Abadía *
}

Plant Nutrition Department, Aula Dei Experimental Station (CSIC), Zaragoza, Spain

Edited by:

Marta Wilton Vasconcelos,

Universidade Católica Portuguesa,

Portugal

Reviewed by:

John M. Ward, University of

Minnesota, USA

Tadakatsu Yoneyama, The University

of Tokyo, Japan

*Correspondence:

Javier Abadía, Plant Nutrition

Department, Aula Dei Experimental

Station (CSIC), PO Box 13034,

E-50080, Zaragoza, Spain

e-mail: jabadia@eead.csic.es
The mechanisms plants use to transport metals from roots to shoots are not completely understood. It has long been proposed that organic molecules participate in metal translocation within the plant. However, until recently the identity of the complexes involved in the long-distance transport of metals could only be inferred by using indirect methods, such as analyzing separately the concentrations of metals and putative ligands and then using in silico chemical speciation software to predict metal species. Molecular biology approaches also have provided a breadth of information about putative metal ligands and metal complexes occurring in plant fluids. The new advances in analytical techniques based on mass spectrometry and the increased use of synchrotron X-ray spectroscopy have allowed for the identification of some metal-ligand species in plant fluids such as the xylem and phloem saps. Also, some proteins present in plant fluids can bind metals and a few studies have explored this possibility. This study reviews the analytical challenges researchers have to face to understand long-distance metal transport in plants as well as the recent advances in the identification of the ligand and metal-ligand complexes in plant fluids.

Keywords: metals, metal complexes, phloem, transport, xylem

\section{INTRODUCTION}

To reach their final destination within the plant (e.g., organelles such as chloroplast or mitochondria) micronutrients taken up from the growth medium, including metals such as Fe, Mn, Zn, and $\mathrm{Cu}$, must follow a complex path through a number of different plant compartments and membrane systems (Clemens et al., 2002; Colangelo and Guerinot, 2006; Briat et al., 2007; Haydon and Cobbett, 2007; Curie et al., 2009; Puig and Peñarrubia, 2009; Conte and Walker, 2011; Sinclair and Krämer, 2012). The vascular system, including the xylem and phloem conduits, is an essential segment for long distance translocation of micronutrients within this path. It has long been proposed that a significant fraction of metals would be present in plant fluids not as free ions but in less reactive chemical forms, e.g., non-covalently bound to organic compounds, to prevent uncontrolled binding and also because free metals often exert some degree of toxicity. The formation of metal complexes provides both solubility and shielding during long-distance transport, since the metallic atom is enveloped by an array of bound molecules or anions (the so-called ligands; in this review only ligands consisting in organic molecules are considered), which donate one or more electron pairs to the metal to form the complexes.

Indirect evidence for long distance, organic ligand-assisted transport of metals has been extensively reported. Possible ligand candidates are a range of small molecules, including organic acids -carboxylates- such as citrate (Cit) and malate (Mal), amino acids [including nicotianamine (NA), histidine (His), cysteine (Cys) and high-affinity Fe(III) chelating compounds derived from NA called phytosiderophores (PSs), such as mugineic (MA) and 2'-deoxymugineic (DMA) acids], as well as peptides and proteins (e.g., metallothioneins). In the case of toxic metals such as $\mathrm{Cd}$, $\mathrm{Hg}$, and others, plants also respond by synthesizing compounds such as the poly-glutathione peptides phytochelatins (PCs) that decrease the amount of free metal ions in plant fluids. Recent papers have reviewed the roles of NA (Curie et al., 2009; Clemens et al., 2013) and PCs (Pal and Rai, 2010) in plant metal homeostasis, the intra- and extracellular excretion of carboxylates (Meyer et al., 2010) and the plant metallo-chaperones (Tehseen et al., 2010). During the last decade, the identification of many genes involved in plant long-distance metal transport has also been achieved, and many reviews have covered this issue in relation to either several metals (Colangelo and Guerinot, 2006; Haydon and Cobbett, 2007; Krämer et al., 2007; Curie et al., 2009; Palmer and Guerinot, 2009; Puig and Peñarrubia, 2009; Krämer, 2010; Waters and Sankaran, 2011) or to specific ones such as Fe (Briat et al., 2007; Kim and Guerinot, 2007; Morrissey and Guerinot, 2009; Conte and Walker, 2011; Sperotto et al., 2012; Thomine and Vert, 2013), Zn (Sinclair and Krämer, 2012), Cu (Yruela, 2009), Mn (Pittman, 2005), and Cd (Mendoza-Cózatl et al., 2011).

To date, analytical data on the actual metal complexes existing in plant fluids are still scarce. This is relevant, because the chemical forms in which a metal occurs in solution (metal speciation) affect solubility, precipitation, acid/base equilibria, electrontransfer reactions, diffusivity, ability to undergo photolysis and others. The metal species existing in any given compartment determine biological activity, including the capability to be a substrate for membrane transport proteins involved in loading and unloading to xylem and phloem, as well as the possibility 
that metal toxicity can occur. This review summarizes the current knowledge on metal species occurring in plant fluids [xylem sap, phloem sap and other fluids such as apoplastic fluid and embryo sac liquid (ESL)], and discusses general problems relevant to these studies as well as the methodological approaches currently used.

\section{METHODS FOR PLANT FLUID SAMPLING AND INHERENT PROBLEMS}

Metal translocation within plants is dynamic, with the composition of plant fluids often changing with time. This mandates to establish an adequate standard sampling protocol, including sampling time and others, which must be applied to all samples so that results are fully comparable. A major limitation in the analysis of plant fluids is the need for samples of adequate purity and in sufficient volume to carry out measurements. The purity of the fluid samples must always be assessed by measuring cytosolic and/or vacuolar components associated to cell rupture. The activities of cytosolic marker enzymes, such as Mal dehydrogenase ( $m d h)$ or others (López-Millán et al., 2000), or the concentrations of $\mathrm{K}$ as a vacuolar marker (Lohaus et al., 2001; Barabasz et al., 2012) are generally used with that purpose.

Xylem sap, the fluid contained in xylem vessels -composed of tracheary elements separated by rather large perforation plates-, is relatively easy to sample (reviewed by Alexou and Peuke, 2013). The most frequently used technique is de-topping plants and letting xylem to bleed after discarding the first drops (López-Millán et al., 2012). Other techniques involve centrifugation of excised stems (López-Millán et al., 2000) or the use of a Schölander pressure chamber (Larbi et al., 2003). With any of these extraction techniques the xylem sap volume sampled could reach several hundreds of $\mu \mathrm{L}$.

The phloem sap, the fluid contained in sieve cells-separated by sieve plates-, is a special case, because there is still controversy about changes in composition induced by wounding (Atkins et al., 2011) and the presence of different types of phloem saps (Zhang et al., 2012). The purity of the phloem sap is usually assessed by measuring sugar concentrations and/or evaluating the presence of Rubisco proteins or transcripts (Giavalisco et al., 2006; Rodríguez-Medina et al., 2011; Lattanzio et al., 2013). Other authors consider $\mathrm{pH}$ values around 8.0 indicative of phloem purity (Ando et al., 2013). Some methods in use for phloem sap sampling (reviewed by Dinant and Kehr, 2013) are those involving an incision near the inflorescence (in Cucurbitaceae, Brassicaceae and some Lupinus species; Lattanzio et al., 2013), those using aphid or leaf-hopper stylectomy (with the disadvantage of resulting in minute phloem sap volumes, $\leq 1 \mu \mathrm{L}$ per cut stylet; Ando et al., 2013), or by exudation of excised shoots maintained at $>80 \%$ relative humidity in a closed chamber (the latter being only a qualitative approach; Marentes and Grusak, 1998). When using insect stylectomy, evaporation during sampling is a relevant issue; accurate determination of the phloem volume has been recently achieved by measuring the droplet diameter as it forms on the tip of the severed aphid stylet (Palmer et al., 2013).

The fluid in the apoplastic space in the leaf (free space outside the plasma membrane) is an interface between the xylem and the symplast. Some methods for leaf apoplastic fluid sampling involve direct centrifugation of leaves without petiole (previously centrifuged at low speed to remove xylem sap from the mid vein; López-Millán et al., 2000) or by using a Schölander pressure chamber (Larbi et al., 2003). Other authors infiltrate the leaves with a solution under vacuum and then obtain by centrifugation a leaf apoplastic wash fluid (Lohaus et al., 2001). Since the latter procedure leads to a dilution of the apoplastic fluid, concentrations should be corrected considering estimations of apoplastic volumes occupied by water and air, using vacuum infiltration with a ${ }^{14} \mathrm{C}$-sorbitol labeled solution and silicone oil, respectively (Lohaus et al., 2001).

Recently, the ESL has been successfully used to study the processes of metal transport in pea seeds (Grillet et al., 2014). This liquid is enriched by the bulk flow of nutrients delivered by the seed coat and feeds the embryo.

\section{METHODOLOGICAL APPROACHES TO UNRAVEL METAL SPECIES OCCURRING IN PLANT FLUIDS}

Until recently, researchers had to rely on indirect methods to putatively identify the chemical forms of metals occurring in plant fluids. These methods were based on separate measurements of the concentrations of metals and possible ligands and the prediction of the existent chemical species by means of titration in "artificial" saps (Liao et al., 2000; Irtelli et al., 2009; Alves et al., 2011) or in silico by using a set of known, experimentally determined stability constants of metal-containing complexes and chemical speciation software; this was always done assuming that chemical equilibrium was achieved (White et al., 1981; López-Millán et al., 2000; Callahan et al., 2006; Harris et al., 2012). However, chemical equilibrium is unexpected in plant fluids, since continuous changes in composition usually occur in these dynamic plant compartments.

Molecular biology approaches have provided key information on putative metal ligands and metal complexes that could play a crucial role in inter- and intra-organ metal transport (see reviews by Briat et al., 2007; Haydon and Cobbett, 2007; Kim and Guerinot, 2007; Milner and Kochian, 2008; Palmer and Guerinot, 2009; Pal and Rai, 2010; Waters and Sankaran, 2011; Leitenmaier and Küpper, 2013; Thomine and Vert, 2013). Genotypes with loss-of-function of genes involved in the trafficking of metals, ligands and/or their metal complexes, as well as metal hyperaccumulator (e.g., T. caerulescens) plant species have been studied. Other approaches include mutant and transgenic lines with impaired or enhanced metal ligand synthesis; a classical example of impaired synthesis is the tomato mutant "chloronerva," which lacks NA (Pich and Scholz, 1996). Transgenic genotypes have also been constructed where the synthesis of ligands such as PCs is restricted to a specific tissue (Gong et al., 2003).

Another approach is searching for molecules with affinity for metals in plant fluids, using their immobilization by metal affinity chromatography (IMAC) followed by identification of the isolated molecules using some of the mass spectrometry (MS) techniques described below (Lattanzio et al., 2013). In this approach, the occurrence of the corresponding metal-ligand complex in plant fluids is only inferred from the presence of suitable ligands.

A further approach to identify metal complexes in plant tissues -including fluids- relies on the identification of the chemical 
environment surrounding the metal by means of synchrotron $\mathrm{X}$-ray absorption spectroscopy (XAS) techniques such as X-ray absorption near edge spectroscopy (XANES) and extended X-ray absorption fine structure spectroscopy (EXAFS) (Lombi et al., 2011; Donner et al., 2012). This has been used for different metals such as Fe (Yoshimura et al., 2000; Terzano et al., 2013), Mn (Yun et al., 1998), Cu (Küpper et al., 2009; Song et al., 2013), Zn (Salt et al., 1999; Küpper et al., 2004; Trampczynska et al., 2010; Lu et al., 2013), Ni (McNear et al., 2010), Cd (Salt et al., 1995; VogelMikus et al., 2010; Huguet et al., 2012; Yamaguchi et al., 2012), Hg (Carrasco-Gil et al., 2011, 2013; McNear et al., 2012), and Pb (Tian et al., 2010; Chu et al., 2012). This technique allows direct in situ metal speciation in plants, without any preliminary extraction or preparation (see reviews by Lombi et al., 2011; Donner et al., 2012; Sarret et al., 2013). However, spectra are difficult to interpret when more than two or three species are dominant, and these techniques are generally used to confirm the presence of known species rather than to find new ones (Monicou et al., 2009). Furthermore, the applications of these techniques have been usually restricted to tissues from metal hyper-accumulators, due to the relatively low sensitivity (metal concentration should be higher than $10 \mu \mathrm{g} \mathrm{g}^{-1}$ dry weight). In spite of that, some data on metal speciation have been reported for sap and vasculature tissues, although mainly in metal hyper-accumulator species. This has been done for $\mathrm{Zn}$ in T. caerulescens (Salt et al., 1999; Küpper et al., 2004; Trampczynska et al., 2010) and Sedum alfredii (Lu et al., 2013), for Cd in Brassica juncea (Salt et al., 1995) and Arabidopsis halleri (Huguet et al., 2012), and for Ni in Alyssum murale (McNear et al., 2010). Recently, the use of highly brilliant synchrotrons as X-ray sources has increased one order of magnitude the sensitivity of EXAFS for trace elements (e.g., below $1 \mu \mathrm{g} \mathrm{g}^{-1}$ dry weight for $\mathrm{Fe}$ ), thus allowing speciation of $\mathrm{Fe}$ in tomato xylem sap (Terzano et al., 2013) and Cd around the vascular bundles in node I -the one beneath the panicle- in Oryza sativa (Yamaguchi et al., 2012). Unfortunately, artifacts can arise from high intensity radiation damage to the sample (i.e., degradation of $\mathrm{Fe}$ (III) complexes with carboxylates and NA, as reported in Terzano et al., 2013).

Recent advances in analytical techniques, and specifically in MS, have enabled a new insight on metal speciation. The use of highly selective and sensitive molecular and metal-specific MS techniques has allowed the identification and quantification of individual, well-defined metal species in plant tissues (including metabolites and proteins), even at sub-nM levels (Meija et al., 2006; Monicou et al., 2009). These approaches generally use hyphenated techniques based on the separation of compounds by high-resolution techniques [e.g., liquid chromatography (HPLC) and capillary electrophoresis (CE)] and the determination of the metals and/or metal complexes by MS techniques [including inductively coupled plasma MS (ICP-MS), electrospray MS (ESI-MS), and others]. These new methodologies (reviewed by Monicou et al., 2009; Khouzam et al., 2012) offer unique advantages for the de novo identification of metallo-metabolites occurring at low concentrations, in particular in plant materials such as plant fluids that do not require multi-step extraction from the plant tissues. Metabolite structures can be elucidated using the empirical formulas of the parent compound and fragment ions (data provided by high-resolution and high-accuracy MS) and the lineage of fragment ions observed in tandem MS or multistage MS (MSn). Furthermore, complexes with metals having more than one stable isotope, such as $\mathrm{Fe}, \mathrm{Zn}, \mathrm{Cu}, \mathrm{Cd}$, and $\mathrm{Hg}$, provide metal-specific isotopic signatures that allow for identification of MS signals corresponding to metal containing molecules (see an example for metal-NA complexes in Rellán-Álvarez et al., 2008). In the five past years, methods based on these analytical techniques have achieved the direct identification of several metal complexes with possible relevance in long distance transport, including carboxylate complexes with $\mathrm{Fe}(\mathrm{III})$ and $\mathrm{Ni}(\mathrm{II})$, NA and PS complexes with Fe(III), Fe(II), Ni(II), Co(II), Mn(II), $\mathrm{Cu}(\mathrm{II})$ and $\mathrm{Zn}(\mathrm{II})$, and His complexes with $\mathrm{Cu}(\mathrm{II})$ (Weber et al., 2006; Xuan et al., 2006, 2007; Rellán-Álvarez et al., 2008, 2010; Dell'mour et al., 2010; Köster et al., 2011a,b; Tsednee et al., 2012). However, until now only a few of these metal-ligand complexes have been really found in plant fluids (see below).

Another MS technique, high-precision multi-collection-ICPMS (developed 20 years ago), which yields high-precision measurements of stable isotopes of transition elements (e.g., $\mathrm{Fe}, \mathrm{Cu}$, and $\mathrm{Zn}$ ), has allowed the study of their fractionation during plant uptake and translocation (reviewed by von Blanckenburg et al., 2009). This technique provides information on the mechanisms involved in metal partitioning within the plant, but not on metal speciation or specific binding environments. Recent studies on fractionation of $\mathrm{Fe}$ and $\mathrm{Cu}$ stable isotopes, using plants relying on Strategy I or II for Fe uptake, have revealed that both metals undergo redox cycling during root-to-shoot translocation in Fe-deficient Strategy I plant species, but not in Strategy II ones (Guelke-Stelling and von Blanckenburg, 2007, 2012; Kiczka et al., 2010; Ryan et al., 2013). A recent in silico study predicted that redox $\mathrm{Fe}$ changes affect $\mathrm{Fe}$ isotopic fractionation, with $\Delta^{56} \mathrm{Fe}$ $\left({ }^{56} \mathrm{Fe} /{ }^{54} \mathrm{Fe}\right.$ ) being $3 \%$ heavier in $\mathrm{Fe}(\mathrm{III})-\mathrm{PS}$ than in $\mathrm{Fe}(\mathrm{II})-\mathrm{NA}$ (Moynier et al., 2013). Even in the absence of redox Fe changes, changes in speciation alone would create up to $1.5 \%$ differences in $\Delta^{56} \mathrm{Fe}$ : Fe(III)-PS is up to $1.5 \%$ heavier than $\mathrm{Fe}(\mathrm{III})$-Cit and $\mathrm{Fe}(\mathrm{II})$-NA is up to $1 \%$ heavier than $\mathrm{Fe}(\mathrm{II})$-Cit (Moynier et al., 2013). These estimations are in agreement with the fact that roots of Strategy-II plants, which rely on Fe(III)-PS uptake, are isotopically heavier (by about $1 \%$ ) than the shoots, where Fe had presumably been transported as $\mathrm{Fe}$ (III)-Cit in the xylem or Fe(II)NA in the phloem. Isotopic variations observed between younger and older leaves could also be explained by the occurrence of Fe acquisition via xylem and phloem (Moynier et al., 2013). Zinc sequestration in roots is mediated by a number of mass dependent processes that favor the heavier isotopes, including binding to cell walls, precipitation in intercellular spaces, binding to high affinity ligands in the root cell and sequestration in the vacuole (Aucour et al., 2011; Caldelas et al., 2011). Translocation processes of $\mathrm{Zn}$ within the plant also lead to significant fractionation of $\mathrm{Zn}$ stable isotopes, since shoots of several plant species were enriched in light isotopes, with the tallest species showing the largest fractionation in the youngest leaves (Moynier et al., 2009). This effect can be modified by the $\mathrm{Zn}$ status in those $\mathrm{Zn}$ hyperaccumulators that accumulate $\mathrm{Zn}$ mainly in the roots (e.g., A. halleri), due to the large fractionation that occurs before shoot Zn's re-translocation. 


\section{METALS IN PLANT FLUIDS}

The study of long distance metal transport has traditionally used differences in metal accumulation ratios (root to shoot metal content ratios) within the plant, considering different scenarios (i.e., growth conditions, genotypes, etc.). Only recently, high-throughput elemental analysis technologies have allowed the characterization of the full ionome in a large number of lines of several plant species (www.ionomicshub.org) (Baxter et al., 2008; Singh et al., 2013). This information, in combination with bioinformatics and genetic tools, has yielded candidate genes coding for transporters as well as gene networks involved in long distance metal transport.

Direct analyses of metals in plant fluids have been carried out in a number of studies, and their concentrations are generally in the $\mu \mathrm{M}$ range (Table $\mathbf{1}$ ). Therefore, the use of sensitive analytical techniques such as graphite furnace atomic absorption spectroscopy (GAAS) or inductively coupled plasma-mass spectrometry (ICP-MS) is mandatory for their determination. Prior to the analyses and immediately after the sampling of plant fluids, metals are usually stabilized in the solution by acidifying it. To avoid metal cross-contamination, high purity acids (ultra trace analysis quality grade) should be used for sample acidification, and also for sample digestion and cleaning of all materials (Husted et al., 2011; Ando et al., 2013). Concentrations found in the xylem sap, phloem sap and leaf apoplastic fluid of different plant species are in the ranges $4-168 \mu \mathrm{M}$ for $\mathrm{Fe}, 0.5-245 \mu \mathrm{M}$ for $\mathrm{Zn}, 0.3-30 \mu \mathrm{M}$ for $\mathrm{Cu}, 4-400 \mu \mathrm{M}$ for $\mathrm{Mn}$ and $\mathrm{nd}-0.1 \mu \mathrm{M}$ for $\mathrm{Cd}$ and Ni (Table 1). These concentrations usually increase when either the metals are in excess in the plant growth medium or when plants (specially those genotypes known as metal stress tolerant) are treated with control metal concentrations after a period of metal deficiency. In these cases concentrations may reach 120$177 \mu \mathrm{M}$ Fe in tomato xylem sap (Orera et al., 2010; Rellán-Álvarez et al., 2010, 2011a), $148 \mu \mathrm{M} Z \mathrm{Zn}$ in sugar beet xylem sap (Sagardoy, 2012), $43 \mu \mathrm{M} \mathrm{Cu}$ in O. sativa phloem sap (Ando et al., 2013), $2300 \mu \mathrm{M}$ Mn in O. sativa leaf apoplastic fluid (Führs et al., 2010) and $1-100 \mu \mathrm{M}$ Cd in O. sativa, B. vulgaris, and S. lycopersicum (Mori et al., 2009; Kato et al., 2010; Sagardoy, 2012). Higher concentrations of metals in plant fluids are also found in hyperaccumulator species: up to $450 \mu \mathrm{M} \mathrm{Ni}$ (Mari et al., 2006) and $524 \mu \mathrm{M}$ Zn (Lasat et al., 1998) in T. caerulense, up to $1750 \mu \mathrm{M}$ $\mathrm{Ni}$ in Alyssum lesbiacum (Kerkeb and Krämer, 2003) and up to $100 \mu \mathrm{M} \mathrm{Cd}$ and $486 \mu \mathrm{M} \mathrm{Zn}$ in A. halleri (Ueno et al., 2008) (Table 1). Altered levels of metals in plant fluids are also found in mutant genotypes as well as in transgenic plants overexpressing or losing the function of either one or several gene components of the uptake, sequestration or transport mechanisms (Nakamura et al., 2008; Ishimaru et al., 2011; Sasaki et al., 2011). The addition of protein synthesis inhibitors or ligands to the growth media has also a large effect on the metal concentrations in plant fluids. For instance, the addition of cycloheximide to the hyper-accumulator A. lesbiacum led to a $70 \%$ reduction of the xylem sap $\mathrm{Ni}$ concentration, whereas the addition of His to the non-accumulator B. juncea increased Ni in xylem sap (Kerkeb and Krämer, 2003).

Transport metal studies have also been approached using radioactive or stable isotopes. Radioactive metal isotopes supplied to plants can be detected by autoradiography, both at the whole plant and/or organ level (Cakmak et al., 2000a,b; Erenoglu et al., 2002). The application of ${ }^{59} \mathrm{Fe}$-citrate to source tissues of pea plants showed that Fe is complexed prior to phloem loading (Grusak, 1994). The high remobilization of ${ }^{109} \mathrm{Cd}$ from the leaves and stem to the maturing grain was associated with high accumulation of Cd in durum wheat grain (Harris and Taylor, 2001). A more recent example is the use of ${ }^{109} \mathrm{Cd}$ autoradiography in A. halleri (a $\mathrm{Zn}$ and Cd hyper-accumulator species) showing that after 3 weeks an enrichment of the leaf petiole, central vein and trichomes occurs, whereas after 9 weeks leaf edges were the most $\mathrm{Cd}$-enriched tissues and $\mathrm{Cd}$ concentrations were lower in regions along leaf vascular bundles (Huguet et al., 2012). A visualization of metals at the microscopic level can be obtained using thin sections. For instance, ${ }^{109} \mathrm{Cd}$ radioisotope imaging using $30-\mu \mathrm{m}$ thickness sections has demonstrated Cd xylem-phloem transfer immediately after root uptake in O. sativa (Kobayashi et al., 2013).

The use of stable metal isotopes and highly selective and sensitive ICP-MS detection has also allowed tracing long-distance transport of metals within plants. Metal sources labeled with stable isotopes and applied to the roots or to leaves were used to evaluate the translocation within the plant of ${ }^{67} \mathrm{Zn}$ (Watmough et al., 1999; Benedicto et al., 2011), ${ }^{57} \mathrm{Fe}$ (Rodríguez-Castrillón et al., 2008; Rojas et al., 2008; Orera et al., 2010), ${ }^{54} \mathrm{Fe}$ (Orera et al., 2010 ), and ${ }^{207} \mathrm{~Pb}$ (Watmough et al., 1999). Recently, the application of stable isotopes combined with laser ablation ICP-MS has allowed to localize and quantify the metal tracer together with other metals in plant tissue thin sections. This has been applied for the quantitative imaging of $\mathrm{Cu}$ and other essential elements (such as $\mathrm{K}, \mathrm{Mg}, \mathrm{Mn}, \mathrm{P}, \mathrm{S}$, and B) in the leaves of the Cu-tolerant plant Elsholtzia splendens treated with ${ }^{65} \mathrm{Cu}$ (Wu et al., 2009). Whereas these are useful approaches for analyzing the spatial distribution or temporal changes of metals within the plant, only a snapshot of the distribution of metal at a given moment can be obtained. In contrast, the Positron-Emitting Tracer Imaging System technique, PETIS, allows for real-time, image quantification studies of the movement of elements in intact plants. The uptake and translocation of metals has been investigated in several graminaceous species using PET tracers ${ }^{52} \mathrm{Fe},{ }^{52} \mathrm{Mn},{ }^{62} \mathrm{Zn}$, and ${ }^{107} \mathrm{Cd}$ (Tsukamoto et al., 2006, 2009; Suzuki et al., 2008; Fujimaki et al., 2010; Ishikawa et al., 2011). For instance, this tool demonstrated the direct translocation of Fe from roots to young leaves via phloem in H. vulgare (Tsukamoto et al., 2009).

\section{LIGANDS IN PLANT FLUIDS}

Organic ligands involved in xylem and phloem metal translocation have been revealed mainly by physiological, genetic, and molecular studies, with the exception of some recent studies performing metabolite profiling using a combination of powerful analytical techniques (e.g., the LC-MS, GC-MS, and NMR analyses of latex of the $\mathrm{Ni}$ hyper-accumulator tree Sebertia acuminata by Callahan et al., 2008). Metal transport is associated with the occurrence in plant fluids of different classes of metal ligands, including: (i) compounds with just only $\mathrm{O}$ atoms as electron donors, such as different carboxylates (mainly Cit and Mal but also some less known ones such as methylated aldaric acid Callahan et al., 2008) and some ortho-dihydroxy phenolic compounds (e.g., protocatechuic acid; Ishimaru et al., 
Table 1 | Metal concentrations (in $\mu \mathrm{M}$ ) in xylem sap, leaf apoplastic fluid and phloem sap in different plant species.

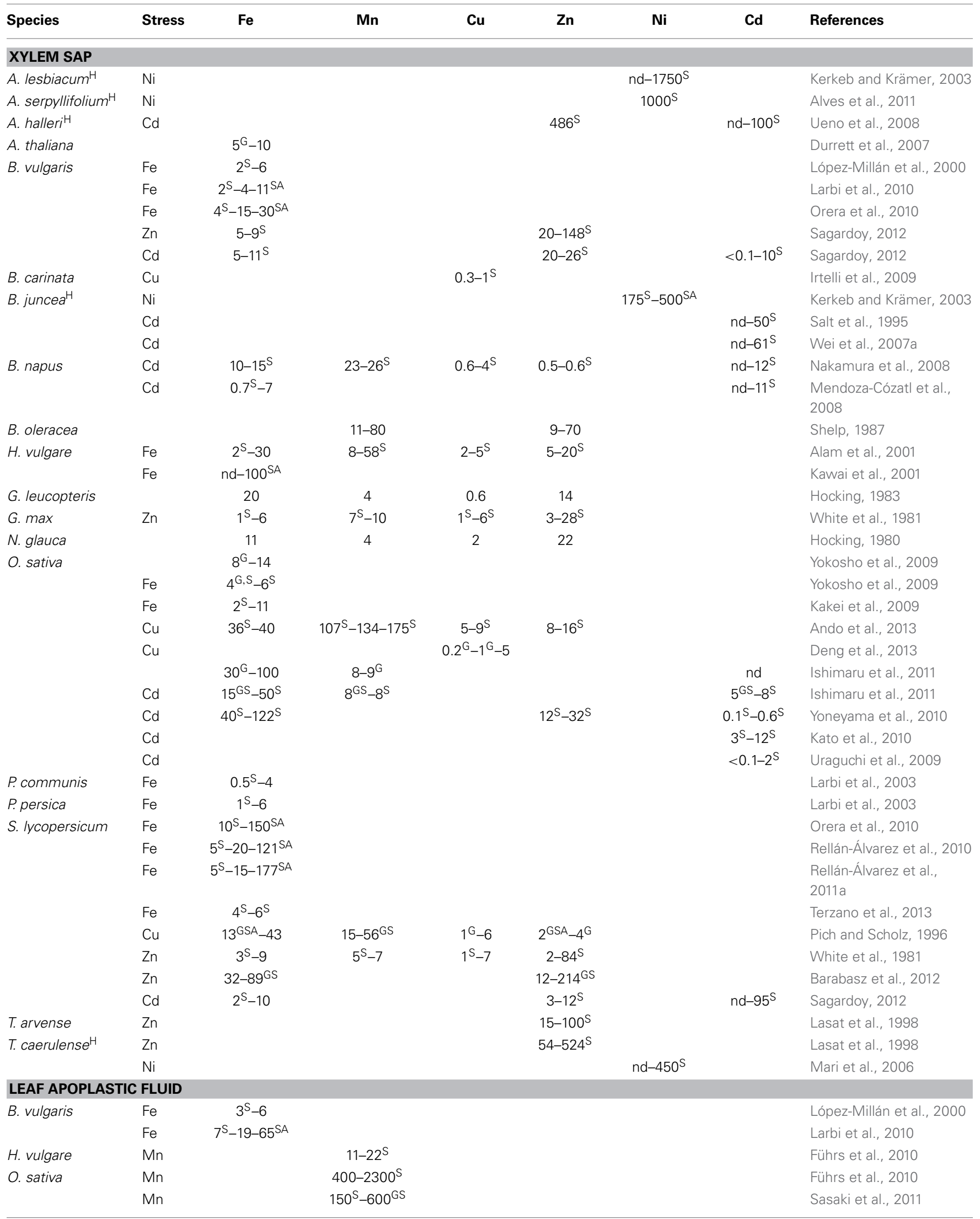


Table 1 | Continued

\begin{tabular}{|c|c|c|c|c|c|c|c|c|}
\hline Species & Stress & $\mathrm{Fe}$ & Mn & $\mathrm{Cu}$ & $\mathrm{Zn}$ & $\mathbf{N i}$ & Cd & References \\
\hline P. communis & $\mathrm{Fe}$ & $2^{S}-5$ & & & & & & López-Millán et al., 2001 \\
\hline S. Iycopersicum & $\mathrm{Zn}$ & $2^{S}-4^{G S}$ & & & $1^{S}-8^{G S}$ & & & Barabasz et al., 2012 \\
\hline \multicolumn{9}{|l|}{ PHLOEM SAP } \\
\hline B. oleracea & & & $4-76$ & & $78-245$ & & & Shelp, 1987 \\
\hline G. leucopteris & & 83 & 24 & 8 & 66 & & & Hocking, 1983 \\
\hline N. glauca & & 168 & 16 & 19 & 243 & & & Hocking, 1980 \\
\hline \multirow[t]{4}{*}{ O. sativa } & $\mathrm{Cu}$ & $54^{S}-67-74^{S}$ & $7^{S}-10$ & $20^{S}-30-43^{S}$ & $14^{S}-22-24^{S}$ & & & Ando et al., 2013 \\
\hline & $\mathrm{Cd}$ & & & & & & nd-18s & Tanaka et al., 2007 \\
\hline & $\mathrm{Cd}$ & $50^{S}-63^{S}$ & & & $34^{S}-115^{S}$ & & $0.1^{S}-0.5^{S}$ & Yoneyama et al., 2010 \\
\hline & $\mathrm{Cd}$ & & & & & & $1^{S}-3^{S}$ & Kato et al., 2010 \\
\hline \multirow[t]{2}{*}{ R. communis } & & $40-64$ & $8-12$ & $16-28$ & $40-74$ & & & $\begin{array}{l}\text { Schmidke and Stephan, } \\
1995\end{array}$ \\
\hline & & 37 & & & & & & Schmidke et al., 1999 \\
\hline
\end{tabular}

Specific cases are marked as follows: ${ }^{S}$ High or low metal supply; ${ }^{A}$ High or low metal supply in combination with a chemical (e.g., histidine, ABA, metal resupply);

${ }^{G}$ Mutant or transgenic genotypes; and ${ }^{H}$ Hyper-accumulator plant species. nd: not detected.

2011); (ii) compounds with $\mathrm{O}$ and $\mathrm{N}$ atoms as electron donors, such as amino acids (proteinogenic ones such as His and nonproteinogenic ones such as NA) and PSs (e.g., MA and DMA); and (iii) compounds with $S$ atoms in which at least one of them acts as an electron donor, such as Cys, S-containing peptides (e.g., glutathione and their derivatives, PCs) and Cys-containing proteins (e.g., metallothioneins).

Carboxylates are usually found in the $\mu \mathrm{M}-\mathrm{mM}$ range in plant fluids, whereas NA, DMA, His, PCs and others are generally in the $\mu \mathrm{M}$ range (examples are given in Table 2 ). Difficulties in determining ligands in plant fluids are inherent to their ability to form metal complexes. The total concentration of ligand (often very low) is distributed in different chemical forms: uncomplexed, complexed to different metals and even complexed to specific metals in different stoichiometries. Therefore, to prevent errors in ligand quantification, the conditions used during sample extraction, treatment and analytical determination seek either the complete dissociation of the existing metal-complexes (while preventing the formation of new ones) or the quantitative formation of the metal complexes [e.g., Fe(III)-PSs]. Also, derivatization of the ligands may be used. An example of the latter is the use of compounds such as fluorenylmethyloxycarbonyl to protect the amino groups of NA by blocking ligand atoms involved in metal complexation (these compounds also tag the ligand with a moiety that favors its detection) (Wada et al., 2007).

Classical analytical methodologies for organic ligands were based on direct HPLC-UV/VIS analyses for carboxylates (LópezMillán et al., 2000), NA (Pich et al., 1994), PSs (Alam et al., 2001) and also for PCs (in the latter case, HPLC-UV/VIS is used in combination with pre- or post-column derivatization with UV/VIS-active tags, such as Ellman's reagent). New methodologies, based generally on HPLC-ESI-MS, have been developed using high resolution MS such as time-of-flight (TOF) MS for carboxylates (Rellán-Álvarez et al., 2011b and references therein) and NA and PSs (Wada et al., 2007; Kakei et al., 2009; Schmidt et al., 2011), Fourier transform ion cyclotron resonance-MS for
NA and PSs (Weber et al., 2006), and quadrupole-TOF MS for NA and PSs (Tsednee et al., 2012). Other techniques have also been used, including CE coupled to UV/VIS (Xuan et al., 2007) or MS detection (Dell'mour et al., 2010), and GC-MS (for NA and/or PSs; Wirth et al., 2009; Rellán-Álvarez et al., 2011a). Nicotianamine and PSs have been analyzed, either using previous derivatization (Wada et al., 2007; Kakei et al., 2009; Schmidt et al., 2011) or by direct analysis (Xuan et al., 2007; Tsednee et al., 2012). In the case of PCs, analytical methods are also based on HPLCMS techniques using either molecular detection (HPLC-ESI-MS and HPLC-ESI-MS/MS) or elemental detection (ICP-MS), and are often combined with derivatization (reviewed by Wood and Feldmann, 2012). For instance, N-(2-ferrocene-ethyl)maleimide is an electroactive pre-column tag that yields thiol-PCs conjugates, which can be separated and quantified by ESI-MS or ICP-MS detection, with detection limits for S at the nM level.

Quantification of ligands in plant fluids has been always done using external calibration with or without internal standardization. The latter is required when using HPLC-ESI-MS-based technologies, because the degree of ionization of a given analyte in different matrices can vary significantly and signal suppression (or enhancement) commonly occurs. Ideally, an isotope-labeled compound should be used as internal standard (IS) per each analyte to achieve accurate quantification; however, since isotope labeled compounds have a limited commercial offer and are quite expensive, either one or two isotope-labeled compounds or structural analogues are generally used. For instance, ${ }^{13} \mathrm{C}$ labelled Mal and succinate have been used for quantification of carboxylates (Rellán-Álvarez et al., 2011b). For quantification of NA and PSs, different ISs, including structural NA analogs such as nicotyl-lysine (Wada et al., 2007) and nicotine (Tsednee et al., 2012), or ${ }^{15} \mathrm{~N}$-labelled NA produced using a recombinant Schizosaccharomyces pombe strain expressing NAS (Schmidt et al., 2011) have been used.

Since many carboxylates have more than one carboxylate group and some also have a $\alpha$-hydroxycarboxylate binding center (i.e., 
Table 2 | Metal ligand concentrations (malate and citrate in $\mathrm{mM}$ and the rest in $\mu \mathrm{M}$ ) in xylem sap, leaf apoplastic fluid and phloem sap.

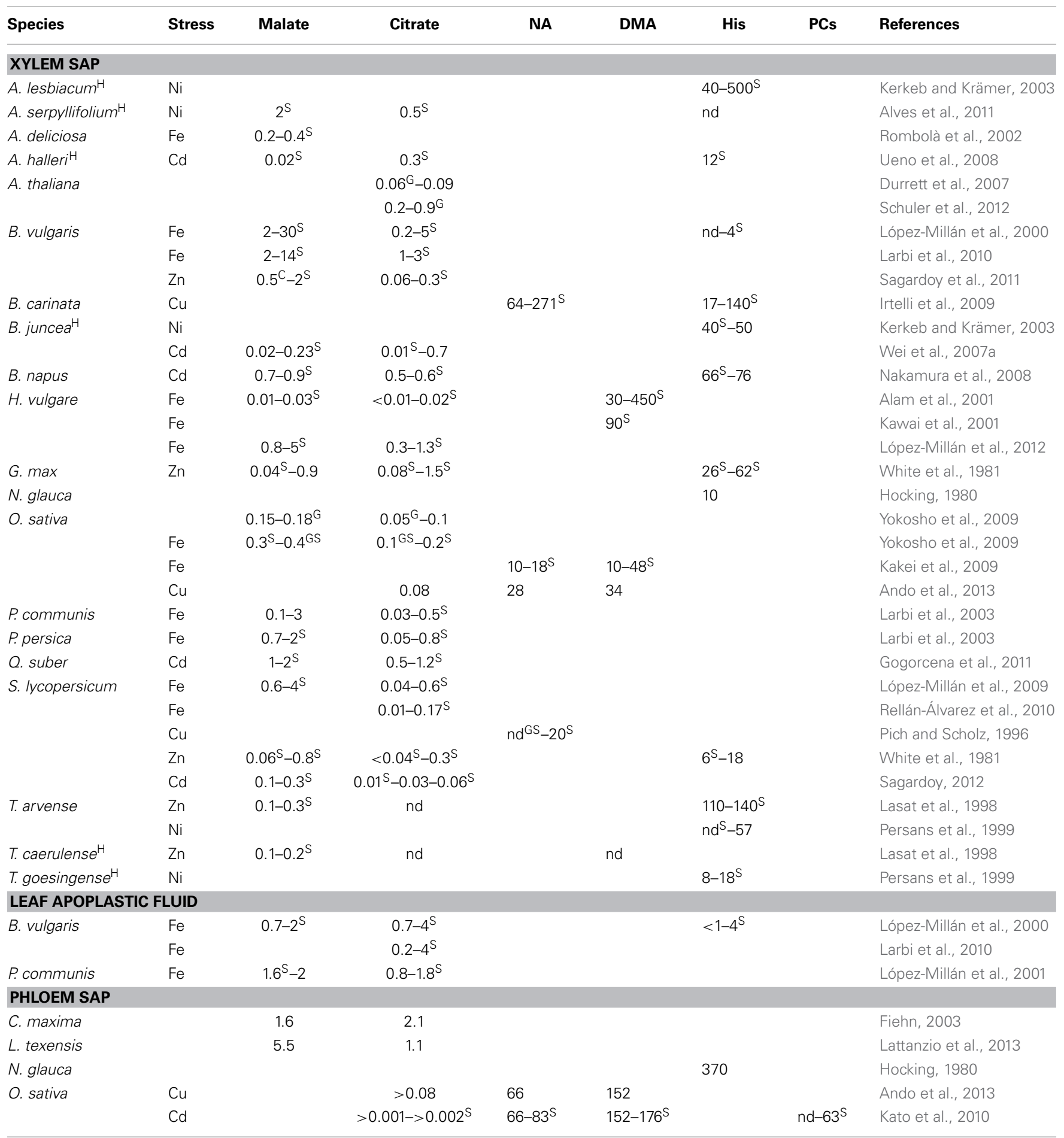

SHigh or low metal supply; ${ }^{G}$ Mutant or transgenic genotypes; and H Hyper-accumulator plant species. Nd, not detected; NA, nicotianamine; DMA, 2'-deoxymugineic acid; His, histidine; PCs, phytochelatins.

$\alpha$-hydroxy acids such as Cit and Mal), they can act as mono- or poly-dentate (bidentate and so on) ligands, and form complexes with several metals (e.g., $\mathrm{Fe}, \mathrm{Mn}, \mathrm{Cu}, \mathrm{Ni}, \mathrm{Zn}, \mathrm{Pb}$, etc.). Carboxylates with shorter chains or closely packed carboxyl groups with adjacent alcohol groups ( $\alpha$-hydroxy acids) form stronger complexes.
These characteristics, as well as the increases in carboxylate levels found in some metal-stressed plants (Table 2), have supported that carboxylates could be associated to long-distance metal transport. For instance, Fe-deficiency causes a well-known increase in carboxylate concentrations (mainly Cit) in xylem sap (Abadía 
et al., 2002; Rellán-Álvarez et al., 2010) and leaf apoplastic fluid (López-Millán et al., 2000, 2001; Larbi et al., 2010). This occurs not only in several Strategy I plant species (Table 2; Abadía et al., 2002 and references therein; Rellán-Álvarez et al., 2010 and references therein) but also in Strategy II plant species (Alam et al., 2001; Yokosho et al., 2009; López-Millán et al., 2012), likely as a result of an increased anaplerotic $\mathrm{C}$ fixation mediated by the root phospoenolpyruvate carboxylase (López-Millán et al., 2000; Andaluz et al., 2002; López-Millán et al., 2012). This increased carboxylate flux in xylem sap would supply $\mathrm{C}$ to the Fe-deficient foliage that is deprived of C skeletons (López-Millán et al., 2000, 2012) and could also increase Fe supply via formation of Cit complexes with extracellular Fe pools (see below). This is in line with the use of citric acid in industry for cleaning and prevention of the clogging of pipes with colloidal and particulate Fe. An increased activity of citrate synthase (CS) and/or an overexpression of CS genes has been reported in plants grown with low Fe supply (e.g., Beta vulgaris López-Millán et al., 2000, Pyrus communis LópezMillán et al., 2001, A. thaliana Thimm et al., 2001, Actinidia deliciosa Rombolà et al., 2002, S. lycopersicum López-Millán et al., 2009, Pisum sativum Jelali et al., 2010, Malus xiaojinensis Han et al., 2012 and citrus Martínez-Cuenca et al., 2013) and more recently in M. xiaojinensis plants grown with excessive Fe supply (Han et al., 2012). In fact, overexpression of an apple CS gene increased tolerance to Fe stress (low and excessive Fe supply) in transgenic A. thaliana and Nicotiana tabacum plants (Han et al., 2012, 2013). Increases in xylem carboxylate concentrations have also been described with other metal stresses, including excess of metals in crop (e.g., Zn in sugar beet Sagardoy et al., 2011 and Cd in tomato Sagardoy, 2012), and forest species (Cd in Quercus suber Gogorcena et al., 2011), as well as in metal hyper-accumulators (e.g., the Zn hyper-accumulator T. caerulescens Lasat et al., 1998, the Cd hyper-accumulator genotype of B. juncea L. Wei et al., 2007a and the Ni hyper-accumulator tree S. acuminata Callahan et al., 2008). It has been hypothesized that the increases in xylem carboxylates may constitute a general mechanism to cope with situations causing reduced photosynthetic activity (Sagardoy et al., 2011).

Catechols such as caffeic and protocatechuic acids are phenolic compounds with two adjacent hydroxyl groups in the aromatic ring, which have very high affinity for Fe(III). These compounds are involved in long-distance transport of $\mathrm{Fe}$ in $O$. sativa, since the mutant phenolics efflux transporter (pez1) had reduced concentrations of $\mathrm{Fe}$, protocatechuic and caffeic acids in the xylem, along with increased root apoplasmic Fe (Ishimaru et al., 2011).

Histidine (His) is one of the strongest metal-coordinating ligands among the proteinogenic amino acids, and has three metal binding sites: carboxylate, $\alpha$-amino and imidazole groups. The coordination to metals through the latter group forms rigid bonds and strong complexes, especially with $\mathrm{Ni}$ and $\mathrm{Cu}$. However, evidence for a role of His in long-distance metal transport in plants is mostly related to $\mathrm{Ni}$ in the xylem of hyper-accumulators of the genus Allysum. Histidine (in the $\mu \mathrm{M}-\mathrm{mM}$ range) and $\mathrm{Ni}$ xylem sap concentrations are significantly and linearly correlated in several Alyssum Ni hyper-accumulators (such as A. lesbiacum) in response to increased metal concentrations in the growth media (Krämer et al., 1996). This increased xylem loading of $\mathrm{Ni}$ is associated with constitutively higher root concentrations of His. Moreover, exogenous applications of His to either the roots or shoots of the non-accumulator plant species Alyssum montanum and Brassica juncea greatly increases the root-to-shoot mobility of $\mathrm{Ni}$ (Kerkeb and Krämer, 2003). In A. lesbiacum shoot His concentrations only increased when plants were exposed to $\mathrm{Ni}$, and the levels of transcripts of the enzymes of the His biosynthesis pathway were constitutively higher in A. lesbiacum than in the non-accumulator $A$. montanum, especially for the first enzyme in the biosynthetic pathway, ATP-phosphoribosyltransferase (ATPPRT) (Ingle et al., 2005). Moreover, the overexpression of an ATP-PRT CDNA in A. thaliana resulted in increases in shoot His and Ni tolerance (Wycisk et al., 2004). However, it has been recently reported that His does not play a role in Ni translocation in the xylem sap of Alyssum ssp. under field conditions (Alves et al., 2011; Centofanti et al., 2013). The Ni-His complex could occur in xylem sap under $\mathrm{N}$-sufficient conditions, whereas under $\mathrm{N}$-limited conditions, such as those usually found in the field, $\mathrm{Ni}$ translocation would occur as a free ion or complexed with carboxylates (Alves et al., 2011).

Nicotianamine (NA) and related molecules such as PSs are multi-dentate aminoacid chelators having more than one $\alpha$ aminocarboxylate binding centers, which confer high affinity not only for Fe but also for other metals such as $\mathrm{Zn}, \mathrm{Cu}, \mathrm{Mn}, \mathrm{Ni}$, and $\mathrm{Cd}$. Nicotianamine has affinity for $\mathrm{Fe}(\mathrm{III})$ and $\mathrm{Fe}(\mathrm{II})$, whereas PSs have an $\alpha$-hydroxycarboxylate binding center that confers selectivity for $\mathrm{Fe}(\mathrm{III})$. Nicotianamine is ubiquitous in higher plants and present in all tissues, and is involved in plant metal trafficking (Curie et al., 2009; Clemens et al., 2013). In the NA-free tomato mutant chloronerva, which displays a strong interveinal chlorosis in young leaves, the long-distance transport of $\mathrm{Cu}$ but not that of $\mathrm{Fe}$ is impaired, indicating the importance of NA in $\mathrm{Cu}$ trafficking (Pich and Scholz, 1996). Unlike NA, PSs are restricted to grasses and secreted to the rhizosphere, and they are responsible for Fe and $\mathrm{Zn}$ acquisition (Suzuki et al., 2006). Both NA and PSs form metal stable complexes at the $\mathrm{pH}$ values occurring in plant fluids (von Wirén et al., 1999, 2000; Rellán-Álvarez et al., 2008). Furthermore, hydroxylated PSs such as MA and epi-MA have a higher affinity for $\mathrm{Fe}(\mathrm{III})$ than the non-hydroxylated DMA at the $\mathrm{pH}$ values from 5 to 7 typical of xylem sap, and this represents a competitive advantage when moving through slightly acid environments (von Wirén et al., 2000).

In xylem sap of O. sativa, NA and DMA concentrations are in the ranges $10-20 \mu \mathrm{M}$ and $10-50 \mu \mathrm{M}$, respectively (Kakei et al., 2009), whereas in phloem sap higher concentrations were found, in the range of 66-83 for NA and $152-176 \mu \mathrm{M}$ for DMA (Kato et al., 2010). Metal stresses caused increases in xylem sap NA or PSs concentrations in several species, including MA and DMA in Fe-deficient H. vulgare (Alam et al., 2001; Kawai et al., 2001), DMA in Fe-deficient O. sativa (Kakei et al., 2009), and NA in Cu-deficient Brassica (Irtelli et al., 2009) and Fe-deficient Prunus persica (Rellán-Álvarez et al., 2011a). Nickel-induced NA root-accumulation occurred in T. caerulescens, a $\mathrm{Cd} / \mathrm{Zn} / \mathrm{Ni}$ hyperaccumulator, but not in $T$. arvense, and this suggests that NA could be involved in Ni translocation via xylem in T. caerulescens, resulting in a higher capacity to transport Ni to shoots (Mari et al., 2006). 
Phytochelatins are oligomers of the tri-peptide glutathione (GluCysGly) and act as metal (Cd, Hg, Zn, and others) chelators through the thiol (-SH) group of Cys. Phytochelatins form a family of structures with increasing repetitions of the -Glu-Cys dipeptide units, followed by a terminal Gly, (-Glu-Cys)n-Gly or (-EC)n-Gly, where $n$ generally ranges from 2 to 5 but can be as high as 11. A number of structural variants have been identified in a wide variety of plant species, and different metals, including $\mathrm{Cd}, \mathrm{Pb}, \mathrm{Zn}$, and $\mathrm{Hg}$, have been found to induce PCs production (reviewed by Pal and Rai, 2010). The occurrence of long-distance transport (either from shoot-to-root or from rootto-shoot) of PCs and some intermediates of their biosynthesis (e.g., $\boldsymbol{\gamma}$-glutamylcysteine) during heavy-metal detoxification was first shown with transgenic and grafted Arabidopsis plants where PCs synthesis was restricted to specific tissues (Gong et al., 2003; Chen et al., 2006; Li et al., 2006). However, the direct determination of PCs in plant fluids has only been achieved more recently: glutathione and PCs were found in the phloem of Cd-treated B. napus (by HPLC coupled to both fluorescence and ESI-MS; Mendoza-Cózatl et al., 2008) and O. sativa (by CE-MS; Kato et al., 2010), and As-treated R. communis (by HPLC-ESI-MS; Ye et al., 2010). Lower concentrations of PCs (or trace levels) were found in the xylem of B. napus (Mendoza-Cózatl et al., 2008) and R. communis (Ye et al., 2010), suggesting that phloem is the major vascular system for PC-facilitated long-distance metal transport.

Proteins can also be involved in metal transport in fluids. A significant fraction of metals has been associated with the high molecular weight fraction in the phloem sap of $R$. communis (Fe Krüger et al., 2002) and O. sativa (Cu Ando et al., 2013 and Cd Kato et al., 2010). Among metal-binding proteins, metallothioneins (MTs) are low molecular weight (5-10 kDa), Cys-rich proteins, which are able to bind a variety of metals by the formation of mercaptide bonds with the numerous Cys residues present in the proteins (see review by Freisinger, 2011). Metallothioneins are implicated in several processes related to metal homeostasis, detoxification, distribution, and redox regulation, in particular under normal (non-stressed) physiological conditions. Evidence supports its role as metal carriers, mainly in the phloem sap. An up-regulation of MTs in $H$. vulgare was found during senescence (when metal remobilization occurs from senescing leaves), heavy metal treatments and $\mathrm{Cu}$ deficiency (Heise et al., 2007). Metallothioneins have been reported to occur in the phloem of Apium graveolens (Vilaine et al., 2003), R. communis (Barnes et al., 2004), O. sativa (Aki et al., 2008) and L. texensis (Lattanzio et al., 2013), when grown under non-stressed conditions. The induction of MTs (MT1) expression in leaf veins (and to a lesser extent in mesophyll cells) in response to $\mathrm{Cu}$ stress in $A$. thaliana suggest that this MT could be important for scavenging $\mathrm{Cu}$ in leaf veins (García-Hernández et al., 1998). Also, in hyper-accumulator plants, MTs could help detoxify the excess $\mathrm{Cu}$ accumulated by the high expression of the Cd/Zn ATPase HMA4 (Leitenmaier and Küpper, 2011, 2013).

\section{CHALLENGES ANALYZING METAL COMPLEXES IN PLANT FLUIDS}

Several challenges are faced when studying metal speciation in plant fluids, because of the changes in metal speciation that may occur at sampling and/or during storage, and especially during sample preparation, separation and determination (Husted et al., 2011). Challenges when attempting the analysis of the metal chemical form(s) existing in a plant fluid occur because: (i) dynamic metal-ligand systems such as those in plant fluids inevitably include labile or transient metal species; (ii) biochemical processes such as enzymatic activities may cause degradation of metal complexes, (iii) metal species occur in plant fluids at very low concentrations (in the $\mu \mathrm{M}$ range; see below; Table 1 ), (iv) the metal complex distribution strongly depends not only on $\mathrm{pH}$, but also on the metal-to-ligand ratios (Weber et al., 2006; Xuan et al., 2006, 2007; Rellán-Álvarez et al., 2008). The latter is specially important in plant fluids, since unlike stable metal chelates with the hexadentate ligands NA and PSs, which always occur with 1:1 stoichiometry, many of the known metal ligands existing in xylem and phloem saps (e.g., amino acids and carboxylates) may act as bi- and tri-dentate ligands, resulting in numerous metal-ligand species with different stoichiometries and charge states (see examples for Fe-Cit complexes in Silva et al., 2009; Rellán-Álvarez et al., 2010). For instance, in a solution with a 1:2 Fe:Cit ratio and $\mathrm{pH}$ 4 , up to thirteen different $\mathrm{Fe}$-Cit species were detected in aqueous solution by ESI-MS, whereas only two species occurred in a solution prepared at 1:100 Fe:Cit ratio at the same $\mathrm{pH}$ (Silva et al., 2009). Also, even for stable metal species, ligand exchange reactions may occur (altering the actual composition of the sample) at any step previous to detection, due to the presence of competing ligands and/or redox mediators. Ligand exchanges have already been reported in the cases of Fe(III)-NA (with Cit; Rellán-Álvarez et al., 2008) and Fe(III)-DMA (with NA; Weber et al., 2006). Some of these challenges are especially critical in separation-based methods (e.g., HPLC, CE), because the separation of the free ligand does change the metal-to-ligand ratio, and also because the $\mathrm{pH}$ may change considerably when organic solvent modifiers are used (Rellán-Álvarez et al., 2008, 2010; Köster et al., 2011a).

Sampling and storage procedures (temperature, light, etc.), can be considered as key aspects to preserve the metal species occurring in samples during the whole analytical process (reviewed by Mesko et al., 2011). Temperature needs to be as low as possible to reduce metal species transformation. For this purpose, lyophilization and shock-freezing in liquid $\mathrm{N}$ are the most common procedures used to preserve metal species in fluids. The latter is considered the safest technique to prevent metal species changes because it can be performed immediately at the sampling site and also because sample is stored in an inert gas atmosphere. Light can cause changes in metal speciation because it can induce electron transfer reactions affecting the stability of the metal complexes and also the structural integrity of the ligands. For instance, photochemical reduction of $\mathrm{Fe}$ (III) complexes with ligands such as di- and tri-carboxylic acids is well known (Bennett et al., 1982), and are accompanied by oxidative decarboxylation of the ligand. This issue could limit the use of irradiation with high intensity synchrotron X-rays for metal speciation (Terzano et al., 2013).

Finally, accurate quantification of metal species, generally performed either on-line or off-line after separation, is currently carried out using metal (ICP-MS) or molecular (ESI-MS) detection, in combination with isotope dilution analysis (IDA) that requires the use of an isotopolog of the analyte. When ICP-MS 
is used, a stable isotope of the metal is added after the separation of the metal complexes. For instance, Rellán-Álvarez et al. (2010) used ${ }^{57} \mathrm{Fe}$ post-column addition to quantify Fe-Cit species in tomato xylem sap. When molecular detection such as ESI-MS is used, the isotopolog should be either a metal complex with a stable isotope-labeled ligand, or alternatively a structural analogue of the ligand. As mentioned above, the limited supply of stable isotope labeled ligands is an additional constraint for metal speciation.

\section{METAL SPECIES IN XYLEM SAP}

Most of the studies exploring the chemical forms of metal complexes in plant fluids have been conducted using xylem sap. Metals occurring in the xylem sap may be preferentially complexed by the more acidic carboxylic acids (existing at concentrations from 2 to $9 \mathrm{mM}$ in the xylem) rather than the much more basic amino acids (existing at concentrations from 1 to $3 \mathrm{mM}$ in the xylem) due to the relatively acidic $\mathrm{pH}$ of this fluid, which is generally in the $\mathrm{pH}$ range from 5 to 6.5 (Harris et al., 2012).

A Fe(III)-Cit complex [tri-Fe(III), tri-Cit complex $\left(\mathrm{Fe}_{3} \mathrm{Cit}_{3}\right)$ ] was found for the first time in the xylem sap of tomato, using an integrated HPLC-MS approach, consisting in hydrophilic interaction liquid chromatography (HILIC) coupled to both ICP-MS and ESI-MS(TOF), combined with the use of stable isotope $\left({ }^{54} \mathrm{Fe}\right)$ labeling; the identification was based on exact molecular mass, isotopic signature, Fe determination and retention time (RellánÁlvarez et al., 2010). Citrate had been considered for many years a likely candidate for Fe xylem transport, but the possible Fe-Cit species in the xylem sap were only predicted from the comigration of $\mathrm{Fe}$ and Cit during paper electrophoresis of xylem sap (Tiffin, 1966) or from in silico calculations (von Wirén et al., 1999; López-Millán et al., 2000, 2001; Rellán-Álvarez et al., 2008). The $\mathrm{Fe}_{3} \mathrm{Cit}_{3}$ complex was only found in xylem samples with $\mathrm{Fe}$ concentrations above $20 \mu \mathrm{M}$ (the limit of detection for the complex), such as those in Fe-deficient plants after Fe-resupply. The complex could not be detected in Fe-deficient and control plants, which have lower xylem sap Fe concentrations. The existence of other Fe-Cit complexes is likely, and the complex $\mathrm{Fe}_{2} \mathrm{Cit}_{2}$ was also detected in Fe-Cit standards along with $\mathrm{Fe}_{3} \mathrm{Cit}_{3}$, with the allocation of Fe between the two complexes depending on the Fe:Cit ratio. Since in plant xylem sap a wide range of Fe to citrate ratios could exist, it is likely that both Fe(III)-Cit species could occur in different conditions (Rellán-Álvarez et al., 2010). Later, other $\mathrm{Fe}$-Cit species were found along with $\mathrm{Fe}_{3} \mathrm{Cit}_{3}$ in $\mathrm{H}$. vulgare leaf extracts using HILIC coupled to high-resolution Fourier transform ion cyclotron resonance (FT-ICR) MS (Köster et al., 2011a). More recently, the Fe speciation in tomato xylem sap was assessed for the first time using XANES on a highly brilliant synchrotron (PETRA III, beamline P06; Terzano et al., 2013). Although this study confirmed the occurrence of $\mathrm{Fe}$ (III)-Cit and also found $\mathrm{Fe}$ (III)-acetate complexes in xylem sap, the authors indicated that complexes found could be artifacts as a result of the high intensity radiation used. Studies with FRD mutants (i.e., Atfrd3 and Osfrdl1), which lack a protein responsible for efflux of Cit in cells of the xylem vasculature, also support the role of Cit as a major ligand responsible for Fe complexation (Durrett et al., 2007; Yokosho et al., 2009). These mutants showed leaf chlorosis and low levels of Fe in xylem and leaves, as well as decreased Cit levels of in the xylem sap. Taken together, all these studies support that $\mathrm{Fe}$-Cit is responsible for the translocation of an important fraction of Fe to the shoot, and that FRD mediated-Cit efflux is required to sustain normal rates of root-shoot Fe delivery. More recently, it was shown that FRD mediated-Cit efflux is also a major player in mobility of $\mathrm{Fe}$ in inter-cellular spaces lacking symplastic connections (Roschzttardtz et al., 2011).

The possible role of NA in long-distance Fe transport in the xylem is still being explored (Curie et al., 2009). However, strong evidence supports that this amino acid is not essential for xylem Fe transport: the NA-deficient tomato mutant chloronerva does accumulate Fe in old leaves (Pich et al., 1994) and the A. thaliana NA synthase (NAS) quadruple mutant (with low levels of NA) also accumulates $\mathrm{Fe}$ in leaves (Klatte et al., 2009). Until now, FeNA chelates have not been detected in xylem sap (Rellán-Álvarez et al., 2010), and in silico and/or in vitro speciation studies tend to exclude NA as a possible xylem Fe carrier at the slightly acidic pH values typical of xylem (von Wirén et al., 1999; Rellán-Álvarez et al., 2008). However, it has been recently suggested that NA may play a role in long distance transport of Fe when carboxylates are in short supply, as it occurs in FRD mutants (Schuler et al., 2012) or in plant species with less acidic xylem such in field-grown Prunus persica trees (where the xylem sap $\mathrm{pH}$ is in the range from 6.5 to 7.5 Larbi et al., 2003; Rellán-Álvarez et al., 2011a). The most accepted role of NA is in intra-organ Fe distribution, where this ligand could be crucial for xylem Fe unloading. Iron distribution within leaves is impeded in the tomato mutant chloronerva (Pich et al., 1994) that also showed a lower presence of $\mathrm{Fe}(\mathrm{II})$ ions in the veins when leaves were analyzed by XANES (Yoshimura et al., 2000). This suggests that the occurrence of Fe as $\mathrm{Fe}(\mathrm{II})-\mathrm{NA}$ complex in leaf veins is crucial for the intra-organ Fe allocation (Yoshimura et al., 2000). No transporter responsible for moving Fe-complexes into the xylem sap has been conclusively identified so far, but it has been suggested that Fe-NA could be effluxed into the xylem by a yellow-stripe-like (YSL) transporter (Colangelo and Guerinot, 2006). Regarding PSs, only a minor peak assigned to $\mathrm{Fe}$ (III)-DMA was found in press sap from the roots of Fe-deficient wheat plants by HILIC-ESI-MS (Xuan et al., 2006).

The $\mathrm{Zn}$ species present in the xylem are still an open question (Clemens et al., 2013). Three studies tackling Zn speciation in xylem sap were carried out using EXAFS or XANES with the hyper-accumulators T. caerulescens (Salt et al., 1999; Monsant et al., 2011) and S. alfredii (Lu et al., 2013). In all cases, although the major fraction of $\mathrm{Zn}$ consisted in free hydrated $\mathrm{Zn}^{2+}$ ions, the remaining fraction was coordinated with carboxylates such as Cit and Mal. The occurrence of $\mathrm{Zn}$-Cit in xylem sap was also predicted by in silico studies in non hyper-accumulator species (White et al., 1981; Mullins et al., 1986). However, other EXAFS study indicated that most of the $\mathrm{Zn}$ in petioles and stems of T. caerulescens is present as Zn-His (Küpper et al., 2004) and a recent study (including the re-evaluation of previous EXAFS spectra from this species) proposes $\mathrm{His}$ as a $\mathrm{Zn}$ ligand within cells and NA as Zn chelator involved in long distance transport (Trampczynska et al., 2010). In a recent room temperature XANES study with $T$. caerulescens intact plants, Zn-His and 
$\mathrm{Zn}$-phytate complexes were found in roots, whereas $\mathrm{Zn}$ (II)-Mal and $\mathrm{Zn}$ (II)-Cit were the major species in shoots (Monsant et al., 2011). In vitro metal exchange experiments also support the existence of the complex $\mathrm{Zn}$ (II)-NA in the xylem sap (Rellán-Álvarez et al., 2008). It has also been speculated that $\mathrm{Zn}$ would be associated with S ligands in Cys, GSH or PCs in hyper-accumulators (Milner and Kochian, 2008). In the Zn hyper-accumulator A. halleri, suppression of NA synthase (NAS2) resulted in strongly reduced NA root accumulation, and a concomitant decrease in root-to-shoot translocation of $\mathrm{Zn}$ (Deinlein et al., 2012). This study found NA and thiols as the dominant $\mathrm{Zn}$ ligands in the low molecular weight fraction of root extracts by using size-exclusion chromatography (SEC)-ICP-MS combined with off-line ESI-MS ligand detection in the $\mathrm{Zn}$-containing $\mathrm{LC}$ fractions. The overexpression of $A$. thaliana ZINC-INDUCED-FACILITATOR1 (ZIF1) altered the subcellular partitioning of NA, which was accumulated in roots, and led to a $\mathrm{Zn}$ accumulation in roots at the expense of shoots (Haydon et al., 2012). This indicates that the formation of $\mathrm{Zn}$ (II)-NA could be responsible for $\mathrm{Zn}$ hyperaccumulation. However, the complex $\mathrm{Zn}$ (II)-NA has never been found in the xylem sap yet. In grasses, a $\mathrm{Zn}$ (II)-DMA complex was detected in press sap from roots of Fe-deficient wheat plants using HILIC-ESI-MS (Xuan et al., 2006).

The $\mathrm{Cu}(\mathrm{II})$-DMA complex has been recently been found in xylem sap of O. sativa (Ando et al., 2013). The Cu(II)-DMA complex was identified by SEC combined with both off-line $\mathrm{Cu}$ determination (using GFAAS) and off-line molecular detection of the complex by ESI-MS, based on exact molecular mass and isotopic signature. In this study, the $\mathrm{Cu}, \mathrm{NA}$, and DMA xylem sap concentrations were 5,28 , and $34 \mu \mathrm{M}$, respectively (the molar ratio DMA:Cu was $c a .7)$. The same complex was already found in press sap from roots of Fe-deficient wheat plants, both using HPLC-MS (Xuan et al., 2006) and CE and UV-VIS detection (Xuan et al., 2007). The presence of Cu(II)-DMA is not unexpected, since it has a quite high stability constant (18.7; Murakami et al., 1989). Nicotianamine and DMA are present in comparable concentrations in the xylem, but $\mathrm{Cu}(\mathrm{II})$-NA has not been found in xylem sap so far, in spite of having a similar stability constant to that of $\mathrm{Cu}$ (II)-DMA (18.6; Callahan et al., 2006). A preferential $\mathrm{Cu}$ complexation by DMA vs. NA was already predicted by in silico speciation (von Wirén et al., 1999). In plant species other than grasses, the low leaf $\mathrm{Cu}$ concentration found in the NA-free tomato mutant chloronerva is in strong support that $\mathrm{Cu}$ (II)-NA is involved in xylem $\mathrm{Cu}$ transport (Pich and Scholz, 1996). The EXAFS spectra of T. caerulescens shoots also suggested the presence of Cu(II)-NA (Mijovilovich et al., 2009). Further support for the role of NA in xylem $\mathrm{Cu}$ transport was obtained when the NA aminotransferase gene from $H$. vulgare was introduced into the non-graminaceous plant $N$. tabacum. When compared to wild type, these transgenic plants showed decreased $\mathrm{Cu}$ concentration in young leaves and flowers (Takahashi et al., 2003), attributable to the depletion of endogenous NA. The occurrence of a Cu-His complex has been reported in the xylem sap from the Ni hyperaccumulator A. lesbiacum by EXAFS (Krämer et al., 1996) and in H. vulgare leaf aqueous extracts by HILIC-FT-ICR/MS (Köster et al., 2011a).
Long-distance Ni transport has been demonstrated in hyperaccumulators (Allysum and Thlaspi species) coordinated with several ligands, including different carboxylates (e.g., Cit, Mal, etc.) and amino acids (e.g., NA and His). An in depth study of Ni ligands using a combination of advanced MS and NMR techniques in the latex of the Ni hyper-accumulator tree S. acuminata revealed the presence of $\mathrm{Ni}$ in complexes with methylated aldaric acid and Cit (Callahan et al., 2008). In this latex, containing $26 \%$ dry matter of $\mathrm{Ni}, \mathrm{Ni}(\mathrm{II})$ was forming complexes of $1: 2$ stoichiometry [ $\mathrm{Ni}(\mathrm{II})$ :carboxylate] with these two carboxylates as well as with Mal, aconitate, erythronate, galacturonate, tartarate, aconitate, and saccharate. A Ni(II)Cit ${ }_{2}$ complex (accounting for $99.4 \%$ of the $\mathrm{Ni}$ ) was previously identified in an aqueous extract of $S$. acuminata using SEC monitorized on-line with ICP-MS, followed by off-line ESI-MS/MS analyses of the Ni-containing SEC-fractions (Schaumlöffel et al., 2003). In leaf extracts of several New Caledonia Ni hyper-accumulator plant species, Ni-Cit complexes were also found as the most prominent $\mathrm{Ni}$ containing ions detected by SEC-ESI-MS/MS (Callahan et al., 2012). In another Ni hyper-accumulator, A. murale, EXFAS studies indicated that $\mathrm{Ni}$ was found coordinated with $\mathrm{Mal}$, His and other low molecular weight compounds in the plant sap and vasculature (McNear et al., 2010), and an in silico speciation study of the xylem sap of the hyper-accumulator A. serpyllifolium predicted approximately $18 \%$ of $\mathrm{Ni}$ bound to organic acids (Alves et al., 2011). However, a detailed study of the metal and ligand concentration in the xylem sap of Alyssum species treated with $\mathrm{Ni}$ for long periods indicated that most of the $\mathrm{Ni}$ in xylem sap of this species is present as the hydrated cation, and that the increases in His and other chelators may constitute only a short term response (Centofanti et al., 2013). The Ni(II)-NA complex is quite stable $(\log K=16.1)$ and accordingly Ni has also been found complexed by NA in hyper-accumulators as well as model plant species. Nickel(II)-NA was found in the xylem sap (Mari et al., 2006) and plant extracts (Vacchina et al., 2003; Ouerdane et al., 2006) of T. caerulescens, in a water extract of the latex in S. acuminata (Schaumlöffel et al., 2003), and in leaf extracts of New Caledonia Ni hyper-accumulator plant species (Callahan et al., 2012), using SEC-ESI-MS/MS or SEC in combination with ICP-MS detection and off-line ESI-MS/MS. In Arabidopsis xylem sap, the Ni(II)-NA complex was also detected using both HPLCMS (Xuan et al., 2006) and CE coupled to UV-VIS (Xuan et al., 2007). On the other hand, studies on natural variation among Arabidopsis accessions indicated that a Ni(II)-Mal complex may also be involved in translocation of $\mathrm{Ni}$ from roots to shoots (Agraval et al., 2013).

In the case of toxic metals such as $\mathrm{Cd}$, complexation with organic ligands in xylem vessels may not be necessary, because toxicity exerted in this apoplastic, extracellular system is low and may not require a metal detoxification strategy. In fact, using ${ }^{113} \mathrm{Cd} \mathrm{NMR}$ analysis combined with a stable isotope $\left({ }^{113} \mathrm{Cd}\right)$ labeling technique, $\mathrm{Cd}$ was found as an ionic form in A. halleri xylem sap (Ueno et al., 2008). However, several EXAFS spectroscopy studies indicate that $\mathrm{Cd}$ is coordinated with $\mathrm{O}$ or $\mathrm{N}$ ligands in B. juncea xylem sap (Salt et al., 1995) and with $\mathrm{O}$ in aerial parts of T. caerulescens (Küpper et al., 2004), A. halleri 
(Huguet et al., 2012) and T. praecox (Vogel-Mikus et al., 2010). In roots of $B$. juncea, a possible coordination of $\mathrm{Cd}$ with $\mathrm{S}$ ligands was also reported (Salt et al., 1995), with the bond length being similar to that of a purified Cd(II)-PC complex, supporting the occurrence of Cd(II)-PC complexes in plants (Salt et al., 1995). The occurrence of Cd association with PCs in the xylem sap of B. juncea has been proposed using SEC and off-line metal GFAAS, and using the retention times of several $\mathrm{Cu}$-complexes with low molecular weight ligands (including PCs, GSH, Cys, organic acids, and inorganic anions) as a mean for identification (Wei et al., 2007b).

The chemical form of $\mathrm{Al}$ in xylem sap has been identified as the Al-Cit complex using ${ }^{27} \mathrm{Al}-\mathrm{NMR}$ analysis in several Al hyper-accumulators, including Fagopyrum esculentum (Ma and Hiradate, 2000), Melastoma malabathricum (Watanabe and Osaki, 2001) and Camellia sinensis (Morita et al., 2004). Since $\mathrm{Al}$ in roots was as an Al-oxalate (1:3) complex, ligand exchange from oxalate to Cit should occur in these plant species ( $\mathrm{Ma}$ and Hiradate, 2000; Watanabe and Osaki, 2001).

\section{METAL SPECIES IN PHLOEM SAP}

The distribution of micronutrients to developing organs of plants depends to a great extent on phloem transport. Unlike xylem, phloem consists of columns of living cells. Metals are sparingly soluble at the alkaline $\mathrm{pH}$ values typical of the phloem sap $(\mathrm{pH}$ range from 7 to 8 ), and they are also highly reactive species, with some of them such as Fe undergoing easily changes of valence that favor the production of highly reactive oxygen species via Fenton reactions. Therefore, metal complexation with appropriate ligands can provide solubility and shielding during phloem transport of metals to the nutrient sinks.

In the phloem sap of O. sativa, Fe has been found predominantly $(77 \%)$ associated with high molecular weight molecules (using a $3 \mathrm{kDa}$ membrane filter; Nishiyama et al., 2012). In this study, Fe-containing compounds or complexes of $10-30 \mathrm{kDa}$ and the Fe(III)-DMA complex were detected in the phloem sap using anion exchange HPLC separation followed by an identification based on Fe determination and the comparison of the retention time with those of standards, in combination with exact molecular mass and Fe isotopic signature obtained using ESI-MS(TOF). A protein capable to bind Fe was described in the phloem sap of R. communis (ITP; Iron Transport Protein; Krüger et al., 2002) using two-dimensional gel electrophoresis protein separation (2DE SDS-PAGE) followed by electro-blotting to PVDF membranes and staining of Fe-containing proteins with Ferene. Recently, two more low molecular weight Fe-binding proteins were also identified in L. texensis phloem sap using a similar approach combined with Fe affinity chromatography, although none of them are considered candidates for Fe transport (Lattanzio et al., 2013). The $\mathrm{Fe}(\mathrm{II})$-NA complex has not been found so far in the phloem sap, although in silico and/or in vitro studies support that the Fe-NA complex is likely to occur at the neutral to basic $\mathrm{pH}$ values of the phloem sap (von Wirén et al., 1999; Rellán-Álvarez et al., 2008), and YSL transporters able to transport Fe-NA complexes have been described in Arabidopsis and O. sativa phloem vascular tissues (Curie et al., 2009). Perhaps NA is only important in Fe phloem loading (Schuler et al., 2012), and once in that compartment Fe may be transported in another form such as bound to proteins.

Almost all $\mathrm{Zn}$ in the O. sativa phloem sap was found associated with low molecular weight molecules when a $3 \mathrm{kDa}$ membrane filter was used as a cut-off (Nishiyama et al., 2012). In this study, Zn was identified as the $\mathrm{Zn}(\mathrm{II})$-NA complex, using SEC and off-line Zn determination and off-line ESI-MS, based on exact molecular mass, isotopic signature, and retention time. In L. texensis phloem sap, four low molecular weight $\mathrm{Zn}$-binding proteins were identified using 2-DE SDS-PAGE, nanoLC-MS/MS and Zn affinity chromatography, one of them being a metallothionein-like protein type $2 \mathrm{~B}$, but they were not considered as good candidates for Zn transport (Lattanzio et al., 2013).

Regarding $\mathrm{Cu}$, the phloem sap of $O$. sativa has been shown to contain the complexes $\mathrm{Cu}(\mathrm{II})-\mathrm{NA}, \mathrm{Cu}(\mathrm{II})-\mathrm{His}$ and highmolecular-weight compounds $>3 \mathrm{kDa}$ (the latter being at least $30 \%$ of the total $\mathrm{Cu}$ ) (Ando et al., 2013). Copper(II)-NA and $\mathrm{Cu}$ (II)-His were identified using SEC combined with both off-line $\mathrm{Cu}$ determination by GFAAS and molecular detection of the complex in the major $\mathrm{Cu}$-containing fractions. Copper-containing proteins detected in phloem sap so far include $\mathrm{Cu} / \mathrm{Zn}$-superoxide dismutase, a $\mathrm{Cu}$-chaperone (CCH homolog) and several MTs in O. sativa (Aki et al., 2008) and L. texensis (Lattanzio et al., 2013).

A Cd-containing complex has not been directly identified in the phloem sap so far. However, $90 \%$ of the Cd in the phloem sap from Cd-treated $O$. sativa plants was found in a complexed form using SEC-ICP-MS (Kato et al., 2010). Based on the elution times of in vitro prepared $\mathrm{Cd}$-complexes with glutathione and several PCs and on the changes caused on Cd elution by sap digestion with proteinase $\mathrm{K}$, it was proposed that $\mathrm{Cd}$ was found associated with a $13 \mathrm{kDa}$ protein and $\mathrm{SH}$-containing compounds. Cadmium has also been associated with $\mathrm{S}$ in the phloem and companion cells of $A$. thaliana using energy-dispersive X-ray microanalysis (van Belleghem et al., 2007). This, along with the occurrence of PCs in phloem of Cd-treated plants (see above) suggest the occurrence of Cd-PC complexes in the phloem sap.

Much less information is available on the chemical forms of other metals in the phloem sap. In R. communis, Mn was detected in association with low molecular peptides (van Goor and Wiersma, 1976), while Ni was shown to be complexed with negatively charged organic compounds with a molecular weight in the range of 1000-5000 Da (Wiersma and van Goor, 1979).

\section{METAL SPECIES IN OTHER FLUIDS}

The ESL is a fluid that facilitates metal transport from the seed coat to the embryo. Iron speciation in isolated P. sativum ESL was achieved using an integrated analytical approach, combining XANES, HILIC-ICP-MS, and HILIC-ESI-MS (Grillet et al., 2014). The application of the XANES technique indicated that most of the Fe was present as Fe(III), probably associated to carboxylates-although the XANES spectra of Fe-Cit and Fe-Mal could not be distinguished-with only a minor amount of $\mathrm{Fe}(\mathrm{II})$ species being present. Most $(88 \%)$ of the Fe occurring in the ESL was found as the species $\mathrm{Fe}(\mathrm{III})_{3} \mathrm{Cit}_{2} \mathrm{Mal}_{2}, \mathrm{Fe}(\mathrm{III})_{3} \mathrm{Cit}_{3} \mathrm{Mal}$ (both are mixed ligand species) and $\mathrm{Fe}(\mathrm{III}) \mathrm{Cit}_{2}$; only a minor amount of $\mathrm{Fe}(\mathrm{II})-\mathrm{NA}$ was found using HILIC separation coupled to the two cited MS detectors. Metal species were identified 
based on elution time, Fe determination, exact mass determination, isotopic signature, and $\mathrm{MS}^{2}$ fragmentation pattern of the Fe species as identification tools. Pea embryos are capable of reducing $\mathrm{Fe}$ (III) in these complexes by effluxing to the ESL high amounts of ascorbate that chemically reduce $\mathrm{Fe}(\mathrm{III})$ from the Fe-Cit and Fe-Mal complexes. Ascorbate efflux also occurs in A. thaliana embryos and is significantly decreased, along with Fe concentrations, in ascorbate deficient mutants (Grillet et al., 2014). These data provide support for a new local Fe transport system that may play a major role to control Fe loading in seeds in dicotyledonous plants.

Apoplastic fluid composition is determined by the balance of import via xylem, absorption by cells, and export by phloem, and plays important roles in the transport and storage of mineral nutrients (Sattelmacher, 2001). However, as far as we know, there are no reports tackling direct metal speciation on apoplastic fluids. In silico calculations have been carried out to speciate Fe in leaf apoplastic fluid of B. vulgaris (López-Millán et al., 2000; Larbi et al., 2010) and field-grown P. communis (López-Millán et al., 2001) using experimental concentrations of Fe, inorganic ions, carboxylates, sugars and amino acids measured from fluids isolated from Fe-sufficient and Fe-deficient plants. In both plant species, Fe was predicted to occur in the leaf apoplastic fluid as Fe-Cit complexes, with FeCitOH and $\mathrm{Fe}(\mathrm{III}) \mathrm{Cit}_{2}$ being the major species. The effect of Fe deficiency altered the balance between these two Fe-Cit species and the contribution of $\mathrm{Fe}(\mathrm{III}) \mathrm{Cit}_{2}$ increased with Fe deficiency in B. vulgaris, whereas in P. communis $\mathrm{Fe}$ (III) $\mathrm{Cit}_{2}$ was lower in Fe-deficient trees.

\section{SUMMARY AND CONCLUDING REMARKS}

The new developments in MS techniques and the increased use of $\mathrm{X}$-ray spectroscopy methods at synchrotron facilities have permitted the discovery of a number of natural metal species (ca. 19) in xylem and phloem saps (Figure 1; clear symbols). Moreover, evidence supporting the occurrence in such fluids of further putative metal species ( $c a$. 15) has been provided by means of physiological studies, many of them applying molecular biology tools (Figure 1; faded symbols). Approximately $50 \%$ of the confirmed metal species and $27 \%$ of the putative ones have been reported in the xylem sap of plants (mostly hyper-accumulators) treated with high metal supply including $\mathrm{Zn}, \mathrm{Ni}$, and $\mathrm{Cd}$. The second most abundant group of metal species has been described in the phloem sap of plants (including grasses) grown at low and adequate metal supply, and accounts for $37 \%$ of the confirmed metal species and 33\% of those considered putative. This second (phloem) group includes mainly species containing $\mathrm{Fe}$ and $\mathrm{Cu}$. Metal carboxylate complexes have always been found in xylem, whereas metals associated with proteins or high molecular weight compounds have been reported in phloem. Complexes with high affinity metal ligands (e.g., NA for $\mathrm{Cu}$ and $\mathrm{Zn}$, PSs for Fe and PCs for Cd) have been commonly found in phloem sap, where complexation is needed to ensure metal solubility at the existing high $\mathrm{pH}$ as well as to avoid uncontrolled binding of metals in living cells, ensuring metal transport and delivery to sinks. Also, high affinity metal ligands have been found as metal carriers in the xylem sap when plants are grown with low or high metal supply. When metal availability is scarce, organic ligand-assisted xylem transport (e.g., Fe complexed by carboxylates or DMA) can increase transport efficiency, because complexation ensures metal delivery, while avoiding unwanted reactions and scavenging any metal pools occurring in the apoplast. Under conditions of high metal supply, organic ligand-assisted xylem transport (e.g., Ni-NA or Cd-PCs) may attenuate the toxicity derived of the exceptionally high metal concentrations as well as to ensure a correct delivery of other metals.

Most of the knowledge on metal complexes in xylem and phloem has been gained using plants (mostly hyperaccumulators) grown on hydroponics with either a short-time excess metal supply treatment or with a established metal deficiency followed by a short-time metal re-supply treatment (the latter in the case of $\mathrm{Fe}$ or $\mathrm{Zn}$ ). Since these conditions are far from the natural ones, some of the reported metal species can differ from the actual complexes existing in plants in natural conditions (Centofanti et al., 2013). The reason to use such growth conditions is to force upwards the metal concentrations usually found in plant fluid samples (which rarely are $>50 \mu \mathrm{M}$; Table 1 ). These low concentrations make particularly challenging the speciation of metals in plant fluids in natural conditions. Also, plant fluids contain ions, sugars, proteins and other biomolecules along with the metal of interest and the rest of metals. This leads to a delicate balance among several metal species, which can include free metal ions and metal complexes having a great diversity of size, charge, and stability. Therefore, the direct analysis of the metal species in plant fluids requires of highly conservative (avoiding any alteration of sample that can damage metal species), sensitive and selective analytical techniques. Unfortunately, none of different techniques available comply with all of these characteristics.

$\mathrm{X}$-ray spectroscopy methods are non-invasive and apparently conservative, although damage of the sample can occur, but they are much less sensitive than ICP-MS and much less selective than ESI-MS/MS. In contrast, MS-based techniques need to be combined with separation methodologies that are inherently invasive since they carry out the separation of the sample in fractions of different characteristics (e.g., molecular size in SEC), and this can significantly affect the distribution of metal chemical forms, particularly in the case of weak metal complexes specially sensitive to changes in $\mathrm{pH}$ and ligand-to-metal ratios. For these reasons, metal species found using MS techniques usually require confirmation using alternative separation methods to validate the actual existence of such metal-complexes in the samples, and sometimes alternative detection methods (e.g., NMR of isolated fractions) are needed to elucidate identity. Ultimately, the occurrence of the metal complexes identified via MS should be also confirmed in intact samples with XAS methods. On the other hand, the use of X-ray spectroscopy methods requires having pure standards of putative metal species, because data interpretation relies on linear combination fitting procedures where the sample spectra is fitted using those of standard compounds. Also, XAS techniques can hardly give any information on well-defined metal species when the sample contains several species with similar XANES spectra (e.g., metal complexes with carboxylates). Therefore, XAS also needs complementary techniques (e.g., ESI-MS/MS) to provide putative metal species as well as to confirm the correct identity of the metal species occurring in the samples.

The path of any given metal to its final destination (e.g., the chloroplast) involves transport across multiple membranes 


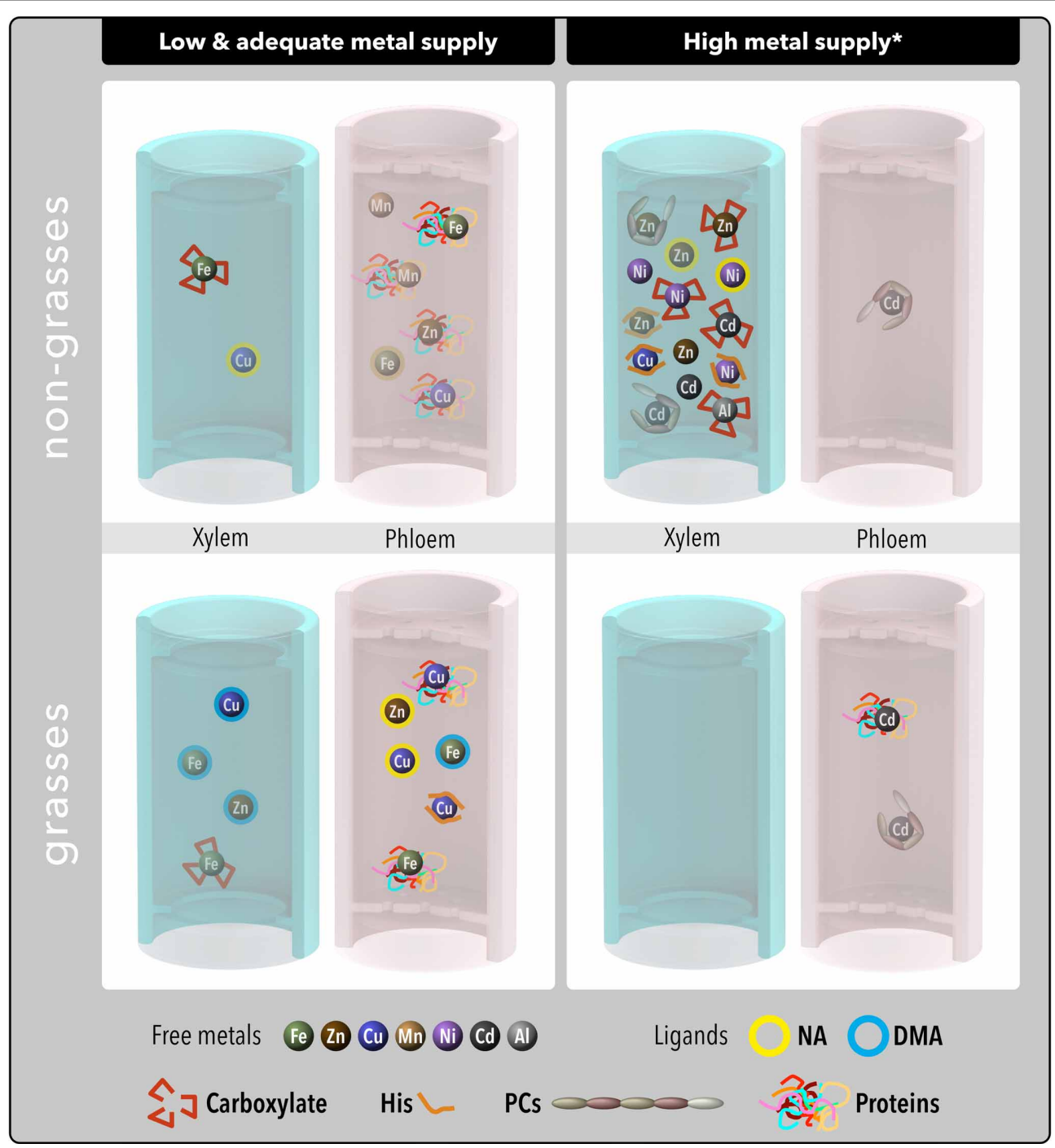

FIGURE 1 | Schematic representation showing the metal species found in the xylem and phloem saps of non-grass (upper panels) and grass plant species (lower panels) grown at low and adequate metal supply (left panels) or at high metal supply (right panels). Metals occurred in free ionic forms and in complexes with different ligands such as nicotianamine (NA), 2'-deoxymugineic acid (DMA), carboxylates (e.g., citrate), histidine (His), phytochelatins (PCs) and proteins. Putative metal species proposed to occur in plant fluids as supported by strong evidence from indirect approaches (e.g., molecular biology and others) are shown with faded symbols. *Most of the data with high metal supply have been described in metal hyper-accumulator plant species. mediated by different transporter proteins and most likely metal complexation by different ligands in each compartment within the path. Although a complete picture of this complex process is still lacking even for one metal, an increasingly more complete and accurate knowledge of the metal species in plant fluids would be achieved performing studies that integrate molecular biology approaches, untargeted analyses of plant fluids using complementary MS-based and NMR techniques, and targeted XAS methods. The limits of detection and quantification of the techniques actually used are still far from ideal to analyze fluids coming from plants grown in natural conditions, and therefore more analytical efforts are required to completely decipher the metal species transported in plant fluids.

\section{ACKNOWLEDGMENTS}

We apologize to those authors whose work has not been cited owing to space constraints or possible oversight. This study was supported by the Spanish Ministry of Economy and Competitiveness (projects AGL2010-16515 and AGL201231988), and the Aragón Government (group A03). Pablo DíazBenito was supported by a MINECO-FPI grant. The authors thank J. Ascaso (Digital Works, Huesca, Spain) for art in Figure 1.

\section{REFERENCES}

Abadía, J., López-Millán, A. F., Rombolà, A. D., and Abadía, A. (2002). Organic acids and Fe deficiency: a review. Plant Soil 241, 75-86. doi: 10.1023/A:1016093317898 
Agraval, B., Czymmek, K. J., Sparks, D. L., and Bais, H. P. (2013). Transient influx of nickel in root mitochondria modulates organic acid and reactive oxygen species production in nickel hyper-accumulator Alysuum murale. J. Biol. Chem. 288, 7351-7362. doi: 10.1074/jbc.M112.406645

Aki, T., Shigyo, M., Nakano, R., Yoneyama, T., and Yanagisawa, S. (2008). Nano scale proteomics revealed the presence of regulatory proteins including three FT-like proteins in phloem and xylem saps from rice. Plant Cell Physiol. 49, 767-790. doi: 10.1093/pcp/pcn049

Alam, S., Kamei, S., and Kawai, S. (2001). Effect of iron deficiency on the chemical composition of the xylem xap of barley. Soil Sci. Plant Nutr. 47, 643-649. doi: 10.1080/00380768.2001.10408428

Alexou, M., and Peuke, A. D. (2013). Methods for xylem sap collection. Methods Mol Biol. 953, 195-207. doi: 10.1007/978-1-62703-152-3_13

Alves, S., Navais, C., Simões Gonçalves, M. de L., and Correia Dos Santos, M. M. (2011). Nickel speciation in the xylem sap of the hiperaccumulator Alyssum serpyllifolium ssp. Lusitanicum growing on serpentine soils of northeast Portugal. J. Plant Physiol. 168, 1715-1722. doi: 10.1016/j.jplph.2011.04.004

Andaluz, S., López-Millán, A. F., Peleato, M. L., Abadía, J., and Abadía, A. (2002), Increases in phosphoenolpyruvate carboxylase activity in iron-deficient sugar beet roots: analysis of spatial localization and post-translational modification Plant Soil 241, 43-48. doi: 10.1023/A:1016000216252

Ando, Y., Nagata, S., Yanagisawa, S., and Yoneyama, T. (2013). Copper in xylem and phloem saps from rice (Oryza sativa): the effect of moderate copper concentrations in the growth medium on the accumulation of five essential metals and a speciation analysis of copper-containing compounds. Funct. Plant Biol. 40, 89-100. doi: 10.1071/FP12158

Atkins, C. A., Smith, P. M. C., and Rodríguez-Medina, C. (2011). Macro-molecules in phloem exudates-a review. Protoplasma 248, 165-172. doi: 10.1007/s00709010-0236-3

Aucour, A. M., Pichat, S., Macnair, M. R., and Oger, P. (2011). Fractionation of stable zinc isotopes in the zinc hyperaccumulator Arabidopsis halleri and nonaccumulator Arabidopsis petraea. Environ. Sci. Technol. 45, 9212-9217. doi: $10.1021 / \mathrm{es} 200874 \mathrm{x}$

Barabasz, A., Wilkowska, A., Ruszczyñsk, A., Bulska, E., Hanikenne, M., Czarny, M., et al. (2012). Metal response of transgenic tomato plants expressing P1BATPase. Physiol. Plant. 145, 315-331. doi: 10.1111/j.1399-3054.2012.01584.x

Barnes, A., Bale, J., Constantinidou, C., Ashton, P., Jones, A., and Pritchard, J. (2004). Determining protein identity from sieve element sap in Ricinus communis L. by quadrupole time of flight (Q-TOF) mass spectrometry. J. Exp. Bot. 55, 1473-1481. doi: 10.1093/jxb/erh161

Baxter, I. R., Vitek, O., Lahner, B., Muthukumar, B., Borghi, M., Morrissey, J., et al. (2008). The leaf ionome as a multivariable system to detect a plant's physiological status. Proc. Nat. Acad. Sci. U.S.A. 105, 12081-12086. doi: 10.1073/pnas.0804175105

Benedicto, A., Hernández-Apaolaza, L., Rivas, I., and Lucena, J. J. (2011). Determination of ${ }^{67} \mathrm{Zn}$ distribution in navy bean (Phaseolus vulgaris L.) after foliar application of ${ }^{67} \mathrm{Zn}$-lignosulfonates using isotope pattern deconvolution J. Agric. Food Chem. 59, 8829-8838. doi: 10.1021/jf2002574

Bennett, J. H., Lee, E. H., Krizek, D. T., Olsen, R. A., and Brown, J. C. (1982). Photochemical reduction of iron. II. Plant related factors. J. Plant Nutr. 5, 335-344. doi: 10.1080/01904168209362962

Briat, J. F., Curie, C., and Gaymard, F. (2007). Iron utilization and metabolism in plants. Curr. Opin. Plant Biol. 10, 276-282. doi: 10.1016/j.pbi.2007.04.003

Cakmak, I., Welch, R. M., Erenoglu, B., Römheld, V., Norvell, W. A., and Kochian, L. V. (2000a). Influence of varied zinc supply on retranslocation of cadmium $\left({ }^{109} \mathrm{Cd}\right)$ and rubidium $\left({ }^{86} \mathrm{Rb}\right)$ applied on mature leaf of durum wheat seedlings. Plant Soil 219, 279-284. doi: 10.1023/A:1004777631452

Cakmak, I., Welch, R. M., Hart, J., Norvell, W. A., Oztürk, L., and Kochian, L. V. (2000b). Uptake and retranslocation of leaf-applied cadmium $\left({ }^{109} \mathrm{Cd}\right)$ in diploid, tetraploid and hexaploid wheats. J. Exp. Bot. 51, 221-226. doi: 10.1093/jexbot/51.343.221

Caldelas, C., Dong, S., Araus, J. L., and Weiss, D. J. (2011). Zinc isotopic fractionation in Phragmites australis in response to toxic levels of zinc. J. Exp. Bot. 62, 2169-2178. doi: 10.1093/jxb/erq414

Callahan, D. L., Baker, A. J. M., Kolev, S. D., and Wedd, A. G. (2006). Metal ion ligands in hyperaccumulating plants. J. Biol. Inorg. Chem. 11, 2-12. doi: 10.1007/s00775-005-0056-7

Callahan, D. L., Roessner, U., Dumontet, V., De Livera, A. M., Doronila, A., Baker, A. J. M., et al. (2012). Elemental and metabolite profiling of nickel hyperaccumulators from New Caledonia. Phytochemistry 81, 80-89. doi: 10.1016/j.phytochem.2012.06.010

Callahan, D. L., Roessner, U., Dumontet, V., Perrier, N., Wedd, A. G., O'Hair, R. A., et al. (2008). LC-MS and GC-MS metabolite profiling of nickel(II) complexes in the latex of the nickel-hyperaccumulating tree Sebertia acuminata and identification of methylated aldaric acid as new nickel(II) ligand. Phytochemistry 69 , 240-251. doi: 10.1016/j.phytochem.2007.07.001

Carrasco-Gil, S., Álvarez-Fernández, A., Sobrino-Plata, J., Millán, R., CarpenaRuiz, R. O., Leduc, D. L., et al. (2011). Complexation of Hg with phytochelatins is important for plant Hg tolerance. Plant Cell Environ. 34, 778-791. doi: 10.1111/j.1365-3040.2011.02281.x

Carrasco-Gil, S., Siebner, H., LeDuc, D. L., Webb, S. M., Millán, R., Andrews, J. C., et al. (2013). Mercury localization and speciation in plants grown hydroponically or in a natural environment. Environ. Sci. Technol. 47, 3082-3090. doi: $10.1021 / \mathrm{es} 303310 \mathrm{t}$

Centofanti, T., Sayers, Z., Cabello-Conejo, M. I., Kidd, P., Nishizawa, N., Kakei, Y., et al. (2013). Xylem exudate composition and root-to-shoot nickel translocation in Alyssum species. Plant Soil 373, 59-75. doi: 10.1007/s11104-013-1782-1

Chen, A., Komives, E. A., and Schroeder, J. I. (2006). An improved grafting technique for mature Arabidopsis plants demonstrates long-distance shoot-to-root transport of phytochelatins in Arabidopsis. Plant Physiol. 141, 108-120. doi: 10.1104/pp.105.072637

Chu, B. B., Luo, L. Q., Xu, T., Yuan, J., Sun, J. L., Zeng, Y., et al. (2012). XANES study of lead speciation in duckweed. Spectrosc. Spect. Anal. 32, 1975-1978. doi: 10.3964/j.issn.1000-0593(2012)07-1975-04

Clemens, S., Deinlein, U., Ahmadi, H., Höreth, S., and Uraguchi, S. (2013). Nicotianamine is a major player in plant $\mathrm{Zn}$ homeostasis. Biometals 26, 623-632. doi: 10.1007/s10534-013-9643-1

Clemens, S., Palmgren, M. G., and Krämer, U. (2002). A long way ahead: understanding and engineering plant metal accumulation. Trends Plant Sci. 7, 309-315. doi: 10.1016/S1360-1385(02)02295-1

Colangelo, E. P., and Guerinot, M. L. (2006). Put the metal to the petal: metal uptake and transport throughout plants. Curr. Opin. Plant Biol. 9, 322-330. doi: 10.1016/j.pbi.2006.03.015

Conte, S. S., and Walker, E. L. (2011). Transporters contributing to iron trafficking in plants. Mol. Plant 4, 464-476. doi: 10.1093/mp/ssr015

Curie, C., Cassin, G., Couch, D., Divol, F., Higuchi, K., Le Jean, M., et al. (2009). Metal movement within the plant: contribution of nicotianamine and yellow stripe 1-like transporters. Ann. Bot. 103, 1-11. doi: 10.1093/aob/men207

Deinlein, U., Weber, M., Schmidt, H., Rensch, S., Trampczynska, A., Hansen, T. H., et al. (2012). Elevated nicotianamine levels in Arabidopsis halleri roots play a key role in zinc hyperaccumulation. Plant Cell 24, 708-723. doi: 10.1105/tpc. 111.095000

Dell'mour, M., Koellensperger, G., Quirino, J. P., Haddadm P. R., Stanetty, C., Oburger, E., et al. (2010). Complexation of metals by phytosiderophores revealed by CE-ESI-MS and CE-ICP-MS. Electrophoresis 31, 1201-1207. doi: 10.1002/elps.200900635

Deng, F., Yamaji, N., Xia, J., and Ma, J. F. (2013). A member of the heavy metal P-Type ATPase OsHMA5 is involved in xylem loading of copper in rice. Plant Physiol. 163, 1353-1362. doi: 10.1104/pp.113.226225

Dinant, S., and Kehr, J. (2013). Sampling and analysis of phloem sap. Methods Mol Biol. 953, 185-194. doi: 10.1007/978-1-62703-152-3_12

Donner, E., Punshon, T., Guerinot, M. L., and Lombi, E. (2012). Functional characterisation of metal(loid) processes in planta through the integration of synchrotron techniques and plant molecular biology. Anal Bioanal. Chem. 402, 3287-3298. doi: 10.1007/s00216-011-5624-9

Durrett, T. P., Gassmann, W. and Rogers, E. E. (2007). The FRD3-mediated efflux of citrate into the root vasculature is necessary for efficient iron translocation. Plant Physiol. 144, 197-205. doi: 10.1104/pp.107.097162

Erenoglu, B., Nikolic, M., Römheld, V., and Cakmak, I. (2002). Uptake and transport of foliar applied zinc $(65 \mathrm{Zn})$ in bread and durum wheat cultivars differing in zinc efficiency. Plant Soil 241, 251-257. doi: 10.1023/A: 1016148925918

Fiehn, O. (2003). Metabolic networks of Cucurbita maxima phloem. Phytochemistry 62, 875-886. doi: 10.1016/S0031-9422(02)00715-X

Freisinger, E. (2011). Structural features specific to plant metallothioneins. J. Biol. Inorg. Chem. 16, 1035-1045. doi: 10.1007/s00775-011-0801-z

Führs, H., Behrens, C., Gallien, S., Heintz, D., Dorsselaer, A. V., Braun, H. P., et al. (2010). Physiological and proteomic characterization of manganese sensitivity 
and tolerance in rice (Oryza sativa) in comparison with barley (Hordeum vulgare). Ann. Bot. 105, 1129-1140. doi: 10.1093/aob/mcq046

Fujimaki, S., Suzui, N., Ishioka, N. S., Kawachi, N., Ito, S., Chino, M., et al. (2010). Tracing cadmium from culture to spikelet: non-invasive imaging and quantitative characterization of absorption, transport, and accumulation of cadmium in an intact rice plant. Plant Physiol. 152, 1796-1806. doi: 10.1104/pp.109. 151035

García-Hernández, M., Murphy, A. and Taiz, L. (1998). Metallothioneins 1 and 2 have distinct but overlapping expression patterns in Arabidopsis. Plant Physiol. 118, 387-397. doi: 10.1104/pp.118.2.387

Giavalisco, P., Kapitza, K., Kolasa, A., Buhtz, A., and Kehr J. (2006). Towards the proteome of Brassica napus phloem sap. Proteomics 6, 896-909. doi: 10.1002/pmic. 200500155

Gogorcena, Y., Larbi, A., Andaluz, S., Carpena, R. O., Abadía, A., and Abadía, J. (2011). Effects of cadmium on cork oak (Quercus suber L.) plants grown in hydroponics. Tree Physiol. 31, 1401-1412. doi: 10.1093/treephys/tpr114

Gong, J. M., Lee, D. A., and Schroeder, J. I. (2003). Long distance root-to-shoot transport of phytochelatins and cadmium in Arabidopsis. Proc. Natl. Acad. Sci. U.S.A. 100, 10118-10123. doi: 10.1073/pnas.1734072100

Grillet, L., Ouerdane, L., Flis, P., Hoang, M. T. T., Isaure, M. P., Lobiñski, R., et al. (2014). Ascorbate efflux as a new strategy for iron reduction and transport in plants. J. Biol. Chem. 289, 2515-2525. doi: 10.1074/jbc.M113.514828

Grusak, M. A. (1994). Iron transport to developing ovules of Pisum sativum. I. Seed import characteristics and phloem iron-loading capacity of source regions. Plant Physiol. 104, 649-655.

Guelke-Stelling, M., and von Blanckenburg, F. (2007). Fractionation of stable iron isotopes in higher plants. Environ. Sci. Technol. 41, 1896-1901. doi $10.1021 / \mathrm{es} 062288 \mathrm{j}$

Guelke-Stelling, M., and von Blanckenburg, F. (2012). Fe isotope fractionation caused by translocation of iron during growth of bean and oat as models of strategy I and II plants. Plant Soil 352, 217-231. doi: 10.1007/s11104-0110990-9

Han, D. G., Wang, L., Wang, Y., Yang, G. H., Gao, C., Yu, Z. Y., et al. (2013). Overexpression of Malus xiaojinensis CS1 gene in tobacco affects plant development and increases iron stress tolerance. Sci. Hortic. 150, 65-72. doi: 10.1016/j. scienta.2012.10.004

Han, D. G., Wang, Y., Zhang, L., Ma, L., Zhang, X. Z., Xu, X. F., et al. (2012) Isolation and functional characterization of $M x C S 1$ : a gene encoding a citrate synthase in Malus xiaojinensis. Biol. Plantarum 56, 50-56. doi: 10.1007/s10535012-0015-4

Harris, N. S., and Taylor, G. J. (2001). Remobilization of cadmium in maturing shoots of near isogenic lines of durum wheat that differ in grain cadmium accumulation. J. Exp. Bot. 52, 1473-1481. doi: 10.1093/jexbot/52.360.1473

Harris, W. R., Sammons, D. R., and Grabiak, R. C. (2012). A speciation model of essential trace elements in phloem. J. Inorg. Biochem. 116, 140-150. doi 10.1016/j.jinorgbio.2012.07.011

Haydon, M. J., and Cobbett, C. S. (2007). Transporters of ligands for essential metal ions in plants. New Phytol. 174, 499-506. doi: 10.1111/j.1469-8137.2007.02051.x

Haydon, M. J., Kawachi, M., Wirtz, M., Hillmer, S., Hell, R., and Krämer, U. (2012). Vacuolar nicotianamine has critical and distinct roles under iron deficiency and for zinc sequestration in Arabidopsis. Plant Cell 24, 724-737. doi: $10.1105 /$ tpc. 111.095042

Heise, J., Krejci, S., Miersch, J., Krauss, G. J., and Humbeck, K. (2007). Gene expression of metallothioneins in barley during senescence and heavy metal treatment. Crop Sci. 47, 1111-1118. doi: 10.2135/cropsci2006.03.0183

Hocking, P. J. (1980). The composition of phloem exudate and xylem sap from tree tobacco (Nicotiana glauca Grah.). Ann. Bot. 45, 633-643.

Hocking, P. J. (1983). The dynamics of growth and nutrient accumulation by fruits of Grevillea leucopteris Meissn., a proteaceous shrub, with special reference to the composition of xylem and phloem sap. New Phytol. 93, 511-529. doi: 10.1111/j.1469-8137.1983.tb02702.x

Huguet, S., Bert, V., Laboudigue, A., Barthes, V., Isaure, M. P., Llorens, I., et al. (2012). Cd speciation and localization in the hyperaccumulator Arabidopsis halleri. Environ. Exp. Bot. 82, 54-65. doi: 10.1016/j.envexpbot.2012.03.011

Husted, S., Persson, D. P., Laursen, K. H., Hansen, T. H., Pedas, P., Schiller, M., et al. (2011). Review: the role of atomic spectrometry in plant science. J. Anal. At. Spectrom. 26, 52-79. doi: 10.1039/c0ja00058b

Ingle, R. A., Mugford, S. T., Rees, J. D., Campbell, M. M., and Smith, J. C. (2005). Constitutively high expression of the histidine biosynthetic pathway contributes to nickel tolerance in hyperaccumulator plants. Plant Cell 17, 2089-2106. doi: 10.1105/tpc.104.030577

Irtelli, B., Petrucci, W. A., and Navari-Izzo, F. (2009). Nicotianamine and histidine/proline are, respectively, the most important copper chelators in xylem sap of Brassica carinata under conditions of copper deficiency and excess. J. Exp. Bot. 60, 269-277. doi: 10.1093/jxb/ern286

Ishikawa, S., Suzui, N., Ito-Tanabata, S., Ishii, S., Igura, M., Abe, T., et al. (2011). Real-time imaging and analysis of differences in cadmium dynamics in rice cultivars (Oryza sativa) using positron-emitting ${ }^{107} \mathrm{Cd}$ tracer. BMC Plant Biol. 11:172. doi: 10.1186/1471-2229-11-172

Ishimaru, Y., Kakei, Y., Shimo, H., Bashir, K., Sato, Y., Sato, Y., et al. (2011). A rice phenolic efflux transporter is essential for solubilizing precipitated apoplasmic iron in the plant stele. J. Biol. Chem. 286, 24649-24655. doi: 10.1074/jbc.M111.221168

Jelali, N., Wissal, M. S., Dell'orto, M., Abdelly, C., Gharsalli, M., and Zocchi, G. (2010). Changes of metabolic responses to direct and induced Fe deficiency of two Pisum sativum cultivars. Environ. Exp. Bot. 68, 238-246. doi: 10.1016/j.envexpbot.2009.12.003

Kakei, Y., Yamaguchi, I., Kobayashi, T., Takahashi, T., Nakanishi, H., Yamakawa, T., et al. (2009). A highly sensitive, quick and simple quantification method for nicotianamine and $2^{\prime}$-deoxymugineic acid from minimum samples using LC/ESI-TOF-MS achieves functional analysis of these components in plants. Plant. Cell Physiol. 50, 1988-1993. doi: 10.1093/pcp/pcp141

Kato, M., Ishikawa, S. Inagaki, K., Chiba, K., Hayashi, H., Yanagisa, S., and Yoneyama, T. (2010). Possible chemical forms of cadmium and varietal differences in cadmium concentrations in the phloem sap of rice plants (Oryza sativa L.). Soil Sci. Plant Nutr. 56, 839-847. doi: 10.1111/j.1747-0765.2010.00514.x

Kawai, S., Kamei, S., Matsuda, Y., Ando, R., Kondo, S., Ishizawa, A., et al. (2001). Concentrations of iron and phytosiderophores in xylem sap of iron-deficient barley plants. Soil Sci. Plant Nutr. 47, 265-272. doi: $10.1080 / 00380768.2001 .10408390$

Kerkeb, L., and Krämer, U. (2003). The role of free histidine in xylem loading of nickel in Alyssum lesbiacum and Brassica juncea. Plant Physiol. 131, 716-724. doi: 10.1104/pp102.010686

Khouzam, R. B., Szpunar, J., Holeman, M., and Lobiñski, R. (2012). Trace element speciation in food: state of the art of analytical techniques and methods. Pure Appl. Chem. 84, 169-179. doi: 10.1351/PAC-CON-11-08-14

Kiczka, M., Wiederhold, J. G., Kraemer, S. M., Bourdon, B., and Kretzschmar, R. (2010). Iron isotope fractionation during Fe uptake and translocation in alpine plants. Environ. Sci. Technol. 44, 6144-6150. doi: 10.1021/es100863b

Kim, S. A., and Guerinot M. L. (2007). Mining iron: iron uptake and transport in plants. FEBS Lett. 581, 2273-2280. doi: 10.1016/j.febslet.2007.04.043

Klatte, M., Schuler, M., Wirtz, M., Fink-Straube, C., Hell, R., and Bauer, P. (2009). The analysis of Arabidopsis nicotianamine synthase mutants reveals functions for nicotianamine in seed iron loading and iron deficiency responses. Plant Physiol. 150, 251-271. doi: 10.1104/pp.109.136374

Kobayashi, N. I., Tanoi, K., Hirose, A., and Nakanishi, T. M. (2013). Characterization of rapid intervascular transport of cadmium in rice stem by radioisotope imaging. J. Exp. Bot. 64, 507-517. doi: 10.1093/jxb/ers344

Köster, J., Hayen, H., von Wirén, N., and Weber, G. (2011b). Isoelectric focusing of small non-covalent metal species from plants. Electrophoresis 32, 772-781. doi: 10.1002/elps.201000529

Köster, J., Shi, R., von Wirén, N., and Weber, G. (2011a). Evaluation of different column types for the hydrophilic interaction chromatographic separation of iron-citrate and copper-histidine species from plants. J. Chromatogr. A 1218, 4934-4943. doi: 10.1016/j.chroma.2011.03.036

Krämer, U. (2010). Metal hyperaccumulation in plants. Annu. Rev. Plant. Biol. 61, 517-534. doi: 10.1146/annurev-arplant-042809-112156

Krämer, U., Cotter-Howells, J. D., Charnock, J. M., Baker, A. J. M., and Smith, J. A. C. (1996). Free histidine as a metal chelator in plants that accumulate nickel. Nature 379, 635-638. doi: 10.1038/379635a0

Krämer, U., Talke, I. N., and Hanikenne, M. (2007). Transition metal transport. FEBS Lett. 581, 2263-2272. doi: 10.1016/j.febslet.2007.04.010

Krüger, C., Berkowitz, O., Stephan, U., and Hell, R. (2002). A metal-binding member of the late embryogenesis abundant protein family transports iron in the phloem of Ricinus communis L. J. Biol. Chem. 277, 25062-25069. doi: 10.1074/jbc.M201896200

Küpper, H., Goetz, B., Mijovilovich, A., Kupper, F. C., and Meyer-Klaucke, W. (2009). Complexation and toxicity of copper in higher plants. I 
Characterization of copper accumulation, speciation, and toxicity in Crassula helmsii as a new copper accumulator. Plant Physiol. 151, 702-714. doi: 10.1104/pp.109.139717

Küpper, H., Mijovilovich, A., Meyer-Klaucke, W., and Kroneck, P. M. (2004). Tissue- and age-dependent differences in the complexation of cadmium and zinc in the cadmium/zinc hyperaccumulator Thlaspi caerulescens (Ganges ecotype) revealed by $\mathrm{x}$-ray absorption spectroscopy. Plant Physiol. 134, 748-757. doi: 10.1104/pp.103.032953

Larbi, A., Morales, F., Abadía, A., and Abadía, J. (2010). Changes in iron and organic acid concentrations in xylem sap and apoplastic fluid of iron-deficient Beta vulgaris plants in response to iron resupply. J. Plant Physiol. 167, 255-260. doi: 10.1016/j.jplph.2009.09.007

Larbi, A., Morales, F., Abadía, J., and Abadía, A. (2003). Effects of branch solid Fe sulphate implants on xylem sap composition in field-grown peach and pear: changes in Fe, organic anions and pH. J. Plant Physiol. 160, 1473-1481. doi: 10.1078/0176-1617-01010

Lasat, M. M., Baker, A. L. J. M., and Kochian, L. V. (1998). Altered Zn compartmentation in the root symplasm and stimulated $\mathrm{Zn}$ absorption into the leaf as mechanisms involved in $\mathrm{Zn}$ hyperaccumulation in Thlaspi caerulescens. Plant Physiol. 118, 875-883. doi: 10.1104/pp.118.3.875

Lattanzio, G., Andaluz, S., Andrea Matros, A., Calvete, J. J., Kehr, J., Abadía, A., et al. (2013). Protein profile of Lupinus texensis phloem sap exudates: searching for $\mathrm{Fe}$ and $\mathrm{Zn}$ containing proteins. Proteomics 13, 2283-2296. doi: 10.1002/pmic. 201200515

Leitenmaier, B., and Küpper H. (2011). Cadmium uptake and sequestration kinetics in individual leaf cell protoplasts of the $\mathrm{Cd} / \mathrm{Zn}$ hyperaccumulator Thlaspi caerulescens. Plant Cell Environ. 34, 208-219. doi: 10.1111/j.13653040.2010.02236.x

Leitenmaier, B., and Küpper, H. (2013). Compartmentation and complexation of metals in hyperaccumulator plants. Front. Plant Sci. 4:374. doi: 10.3389/fpls.2013.00374

Li, Y., Dankher, O. P., Carreira, L., Smith, A. P., and Meagher, R. B. (2006). The shoot-specific expression of $\gamma$-glutamylcysteine synthetase directs the longdistance transport of thiol-peptides to roots conferring tolerance to mercury and arsenic. Plant Physiol.141, 288-298. doi: 10.1104/pp.105.074815

Liao, M. T., Hedley, M. J., Woolley, D. J., Brooks, R. R., and Nichols, M. A. (2000). Copper uptake and translocation in chicory (Cichorium intybus L. cv. Grasslands Puna) and tomato (Lycopersicon esculentum Mill. cv. Rondy) plants grown in NFT system. I. Copper uptake and distribution in plants. Plant Soil 221, 135-142. doi: 10.1023/A:1004731415931

Lohaus, G., Pennewis, K., Sattelmacher, B., Hussman, M., and Muehling, K. H. (2001). Is the infiltration-centrifugation technique appropriate for the isolation of apoplastic fluid? A critical evaluation with different plant species. Physiol. Plant. 111, 457-465. doi: 10.1034/j.1399-3054.2001.111 0405.x

Lombi, E., Scheckel, K. G., and Kempson, I. M. (2011). In situ analysis of metal(loid)s in plants: state of the art and artefacts. Environ. Exp. Botany. 72, 3-17. doi: 10.1016/j.envexpbot.2010.04.005

López-Millán, A. F., Grusak, M. A., and Abadía, J. (2012). Carboxylate metabolism changes induced by Fe deficiency in barley, a Strategy II plant species. J. Plant Physiol. 169, 1121-1124. doi: 10.1016/j.jplph.2012.04.010

López-Millán, A. F., Morales, F., Abadía, A., and Abadía, J. (2000). Effects of iron deficiency on the composition of the leaf apoplastic fluid and xylem sap in sugar beet. Implications for iron and carbon transport. Plant Physiol. 124, 873-884. doi: 10.1104/pp.124.2.873

López-Millán, A. F., Morales, F., Abadía, A., and Abadía, J. (2001). Iron deficiencyassociated changes in the composition of the leaf apoplast fluid from fieldgrown pear (Pyrus communis L.) trees. J. Exp. Bot. 52, 1489-1498. doi: 10.1093/jexbot/52.360.1489

López-Millán, A. F., Morales, F., Gogorcena, Y., Abadía, A., and Abadía, J. (2009). Organic acid metabolism in iron deficient tomato plants. J. Plant Physiol. 166, 375-384. doi: 10.1016/j.jplph.2008.06.011

Lu, L., Tian, S., Zhang, J., Yang, X., Labavitch, J. M., Webb, S. M., et al. (2013). Efficient xylem transport and phloem remobilization of $\mathrm{Zn}$ in the hyperaccumulator plant species Sedum alfredii. New Phytol. 198, 721-731. doi: 10.1111/nph.12168

Ma, J. F., and Hiradate, S. (2000). Form of aluminium for uptake and translocation in buckwheat (Fagopyrum esculentum Moench). Planta 211, 355-360. doi: $10.1007 /$ s004250000292
Marentes, E., and Grusak, M. A. (1998). Iron transport and storage within the seed coat of developing embryos of pea (Pisum sativum L). Seed Sci. Res. 8, 367-375. doi: 10.1017/S0960258500004293

Mari, S., Gendre, D., Pianelli, K., Ouerdane, L., Lobinski, R., Briat, J. F., et al. (2006). Root-to-shoot long-distance circulation of nicotianamine and nicotianaminenickel chelates in the metal hyperaccumulator Thlaspi caerulescens. J. Exp. Bot. 57, 4111-4122. doi: 10.1093/jxb/erl184

Martínez-Cuenca, M. R., Iglesias, D. J., Talón, M., Abadía, J., López-Millán, A. F., Primo-Millo, E., et al. (2013). Metabolic responses to iron deficiency in roots of Carrizo citrange (Citrus sinensis (L.) Osb. $\mathrm{x}$ Poncirus trifoliata (L) Raf.). Tree Physiol. 33, 320-329. doi: 10.1093/treephys/tpt011

McNear, D. H., Afton, S. E., and Caruso, J. A. (2012). Exploring the structural basis for selenium/mercury antagonism in Allium fistulosum. Metallomics 4, 267-276. doi: $10.1039 / \mathrm{c} 2 \mathrm{mt} 00158 \mathrm{f}$

McNear, D. H., Chaney, R. L., and Sparks, D. L. (2010). The metal hyperaccumulator Alyssum murale uses nitrogen and oxygen donor ligands for Ni transport and storage. Phytochemistry 71, 188-200. doi: 10.1016/j.phytochem.2009.10.023

Meija, J., Montes-Bayón, M., Caruso, J. A., and Sanz-Medel, A. (2006). Integrated mass spectrometry in (semi) metal speciation and its potential in phytochemistry. Trends Anal. Chem. 25, 44-51. doi: 10.1016/j.trac.2005.04.003

Mendoza-Cózatl, D. G., Butko, E., Springer, F., Torpey, J. W., Komives, E. A., Kehr, J., et al. (2008). Identification of high levels of phytochelatins, glutathione and cadmium in the phloem sap of Brassica napus. A role for thiol-peptides in the long-distance transport of cadmium and the effect of cadmium on iron translocation. Plant J. 54, 249-259. doi: 10.1111/j.1365-313X.2008.03410.x

Mendoza-Cózatl, D. G., Jobe, T. O., Hauser, F., and Schroeder, J. I. (2011). Long-distance transport, vacuolar sequestration, tolerance, and transcriptional responses induced by cadmium and arsenic. Curr. Opin. Plant Biol. 14, 554-562. doi: 10.1016/j.pbi.2011.07.004

Mesko, M. F., Hartwig, C. A., Bizzi, C. A., Pereira, J. S. F., Mello, P. A., and Flores, E. M. M. (2011). Sample preparation strategies for bioinorganic analysis by inductively coupled plasma mass spectrometry. Int. J. Mass Spectrom. 307, 123-136. doi: 10.1016/j.ijms.2011.03.002

Meyer, S., Angeli, A. D., Fernie, A. R., and Martinoia, E. (2010). Intra- and extra-cellular excretion of carboxylates. Trends Plant Sci. 15, 40-47. doi: 10.1016/j.tplants.2009.10.002

Mijovilovich, A., Leitenmaier, B., Mayer-Klaucke, W., Kroneck, P. M. H., Götz, B., and Küpper, H. (2009). Complexation and toxicity of copper in higher plants II. Different mechanisms for copper vs. cadmium detoxification in the copper-sensitive cadmium/zinc hyperaccumulator Thlaspi caerulescens (Ganges ecotype). Plant Physiol. 151, 715-731. doi: 10.1104/pp.109.144675

Milner, M. J., and Kochian, L. V. (2008). Investigating heavy-metal hyperaccumulation using Thlaspi caerulescens as a model system. Ann. Bot. 102, 3-13. doi: 10.1093/aob/mcn063

Monicou, S., Szpunar, J., and Lobinski, R. (2009). Metallomics: the concept and methodology. Chem. Soc. Rev. 38, 1119-1138. doi: 10.1039/b713633c

Monsant, A. C., Kappen, P., Wang, Y., Pigram, P. J., Baker, A. J. M., and Tang, C. (2011). In vivo speciation of zinc in Noccaea caerulescens in response to nitrogen form and zinc exposure. Plant Soil. 348, 167-183. doi: 10.1007/s11104-0110887-7

Mori, S., Uraguchi, S., Ishikawa, S., and Arao, T. (2009). Xylem loading process is a critical factor in determining Cd accumulation in the shoots of Solanum melongena and Solanum torvum. Environ. Exp. Bot. 67, 127-132. doi: 10.1016/j.envexpbot.2009.05.006

Morita, A., Horie, H., Fujii, Y., Takatsu, S., Watanabe, N., Yagi, A., et al. (2004) Chemical forms of aluminum in xylem sap of tea plants (Camellia sinensis L.). Phytochemistry 65, 2775-2780. doi: 10.1016/j.phytochem.2004.08.043

Morrissey, J., and Guerinot, M. L. (2009). Iron uptake and transport in plants: the good, the bad and the ionome. Chem. Rev. 109, 4553-4567. doi: $10.1021 / \mathrm{cr} 900112 \mathrm{r}$

Moynier, F., Fujii, T.,Wang, K., and Foriel, J. (2013). Ab initio calculations of the $\mathrm{Fe}(\mathrm{II})$ and $\mathrm{Fe}(\mathrm{III})$ isotopic effects in citrates, nicotianamine, and phytosiderophore, and new Fe isotopic measurements in higher plants. Comp. Rend. Geosci. 345, 230-240. doi: 10.1016/j.crte.2013.05.003

Moynier, F., Pichat, S., Pons, M. L., Fike, D., Balter, V., and Albarède, F. (2009). Isotopic fractionation and transport mechanisms of $\mathrm{Zn}$ in plants. Chem. Geol. 267, 125-130. doi: 10.1016/j.chemgeo.2008.09.017

Mullins, G. L., Sommers, L. E., and Housley, T. L. (1986). Metal speciation in xylem and phloem exudates. Plant Soil 96, 377-391. doi: 10.1007/BF02375142 
Murakami, T., Ise, K., Hayakawa, M., Kamei, S., and Takagi, S. (1989). Stabilities of metal complexes of mugineic acid and their specific affinities for iron(III). Chem Lett. (Jpn.) 18, 2137-2140. doi: 10.1246/cl.1989.2137

Nakamura, S., Akiyama, C., Sasaki, T., Hattori, H., and Chino, M. (2008). Effect of cadmium on the chemical composition of xylem exudates from oilseed rape plants (Brassica napus L.). Soil Sci. Plant Nutr. 54, 118-127. doi: 10.1111/j.17470765.2007.00214.x

Nishiyama, R., Kato, M., Nagata, S., Yanagisawa, S., and Yoneyama, T. (2012). Identification of $\mathrm{Zn}$-nicotianamine and $\mathrm{Fe}-2^{\prime}$-deoxymugineic acid in the phloem sap from rice plants (Oryza sativa L.). Plant Cell Physiol. 53, 381-390. doi: $10.1093 / \mathrm{pcp} / \mathrm{pcr} 188$

Orera, I., Rodríguez-Castrillón, J. A., Moldovan, M., García-Alonso, J. I., Abadía, A., Abadía, J., et al. (2010). Using a dual-stable isotope tracer method to study the uptake, xylem transport and distribution of Fe and its chelating agent from stereoisomers of an $\mathrm{Fe}$ (III)-chelate used as fertilizer in Fe-deficient Strategy plants. Metallomics 2, 646-657. doi: 10.1039/c0mt00018c

Ouerdane, L., Mari, S., Czernic, P., Lebrun, M., and Lobiñski, R. (2006). Speciation of non-covalent nickel species in plant tissue extracts by electrospray QTOFMS/MS after their isolation by 2D size exclusion-hydrophilic interaction LC (SEC-HILIC) monitored by ICP-MS. J. Anal. At. Spectrom. 21, 676-683. doi: $10.1039 / \mathrm{b} 602689 \mathrm{c}$

Pal, R., and Rai, J. P. N. (2010). Phytochelatins: peptides involved in heavy metal detoxification. Appl. Biochem. Biotechnol. 160, 945-963. doi: 10.1007/s12010009-8565-4

Palmer, C. M., and Guerinot, M. L. (2009). Facing the challenges of $\mathrm{Cu}, \mathrm{Fe}$ and $\mathrm{Zn}$ homeostasis in plants. Nat. Chem. Biol. 5, 333-340. doi: 10.1038/nchembio.166

Palmer, L. J., Palmer, L. T., Pritchard, J., Graham, R. D., and Stangoulis, J. C. R. (2013). Improved techniques for measurement of nanolitre volumes of phloem exudate from aphid stylectomy. Plant Methods 9, 18. doi: 10.1186/17464811-9-18

Persans, M. W., Yan, X., Patnoe, J. M. L., Krämer, U., and Salt, D. E. (1999). Molecular dissection of the role of histidine in nickel hyperaccumulation in Thlaspi goesingense (Hailaìcsy). Plant Physiol. 121, 1117-1126. doi: 10.1104/pp.121.4.1117

Pich, A., and Scholz, G. (1996). Translocation of copper and other micronutrients in tomato plants (Lycopersicon esculentum Mill.): nicotianamine-stimulated copper transport in the xylem. J. Exp. Bot. 47, 41-47. doi: 10.1093/jxb/47.1.41

Pich, A., Scholz, G., and Stephan, U. (1994). Iron-dependent changes of heavymetals, nicotianamine, and citrate in different plant organs and in the xylem exudate of two tomato genotypes- nicotianamine as a possible copper translocator. Plant Soil 165, 189-196. doi: 10.1007/BF00008061

Pittman, J. K. (2005). Managing the manganese: molecular mechanisms of manganese transport and homeostasis. New Phytol. 167, 733-742. doi: 10.1111/j.1469-8137.2005.01453.x

Puig, S., and Peñarrubia, L. (2009). Placing metal micronutrients in context: transport and distribution in plants. Curr. Opin. Plant Biol. 12, 299-306. doi: 10.1016/j.pbi.2009.04.008

Rellán-Álvarez, R., Abadía, J., and Álvarez-Fernández, A. (2008). Formation of metal-nicotianamine complexes as affected by $\mathrm{pH}$, ligand exchange with citrate and metal exchange. A study by electrospray ionization time-of-flight mass spectrometry. Rapid Commun. Mass Sp.. 22, 1553-1562. doi: 10.1002/rcm.3523

Rellán-Álvarez, R., El-Jendoubi, H., Wohlgemuth, G., Abadía, A., Fiehn, O., Abadía, A., et al. (2011a). Metabolite profile changes in xylem sap and leaf extracts of strategy I plants in response to iron deficiency and resupply. Front. Plant Sci. 2:66. doi: $10.3389 /$ fpls.2011.00066

Rellán-Álvarez, R., Giner-Martínez-Sierra, J., Orduna, J., Orera, I., Rodríguez-Castrillón, J. A., García-Alonso, J. I., et al. (2010). Identification of a tri-iron(III), tri-citrate complex in the xylem sap of iron-deficient tomato resupplied with iron: new insights into plant iron long-distance transport. Plant Cell Physiol. 51, 91-102. doi: 10.1093/pcp/pcp170

Rellán-Álvarez, R., López-Gomollón, S., Abadía, J., and Álvarez-Fernández, A. (2011b). Development of a new high-performance liquid chromatographyelectrospray ionization Time-of-Flight mass spectrometry method for the determination of low molecular mass organic acids in plant tissue extracts. J. Agric. Food Chem. 59, 6864-6870. doi: 10.1021/jf200482a

Rodríguez-Castrillón, J. A., Moldovan, M., García-Alonso, J. I., Lucena, J. J., GarcíaTome, M. L., and Hernández-Apaolaza, L. (2008). Isotope pattern deconvolution as a tool to study iron metabolism in plants. Anal. Bioanal. Chem. 390, 579-590. doi: 10.1007/s00216-007-1716-y
Rodríguez-Medina, C., Atkins, C. A., Mann, A. J., Jordan, M. E., and Smith, P. M. C. (2011). Macromolecular composition of phloem exudate from white lupin (Lupinus albus L.). BMC Plant Biol. 11:36. doi: 10.1186/1471-2229-11-36

Rojas, C. L., Romera, F. J., Alcántara, E., Pérez-Vicente, R., Sariego, C., GarcíaAlonso, J. I., et al. (2008). Efficacy of $\mathrm{Fe}(o, o$-EDDHA) and $\mathrm{Fe}(o, p$-EDDHA) isomers in supplying $\mathrm{Fe}$ to Strategy I plants differs in nutrient solution and calcareous soil. J. Agric. Food Chem. 56, 10774-10778. doi: 10.1021/jf80 22589

Rombolà, A. D., Brüggemann, W., López-Millán, A. F., Tagliavini, M., Abadía, J., Marangoni, B., et al. (2002). Biochemical responses to iron deficiency in kiwifruit (Actinidia deliciosa). Tree Physiol. 22, 869-875. doi: 10.1093/treephys/ 22.12.869

Roschzttardtz, H., Séguéla-Arnaud, M., Briat, J. F., Vert, G., and Curie, C. (2011). The FRD3 citrate effluxer promotes iron nutrition between symplastically disconnected tissues throughout Arabidopsis development. Plant Cell 23 2725-2737. doi: 10.1105/tpc.111.088088

Ryan, B. M., Kirby, J. K., Degryse, F., Harris, H., McLaughlin, M. J., and Scheiderich, K. (2013). Copper speciation and isotopic fractionation in plants: uptake and translocation mechanisms. New Phytol. 199, 367-378. doi: 10.1111/nph.12276

Sagardoy, R. (2012). "Effects of Zn and Cd toxicity on metal concentrations in the xylem sap of B. vulgaris and S. esculentum," in Study of Zn and Cd Homeostasis in Higher Plants. Ph.D. Thesis, Zaragoza: University of Zaragoza.

Sagardoy, R., Morales, F., Rellán-Álvarez, R., Abadía, J., Abadía, A., and LópezMillán, A. F. (2011). Carboxylate metabolism in sugar beet plants grown with excess Zn. J. Plant Physiol. 168, 730-733. doi: 10.1016/j.jplph.2010.10.012

Salt, D. E., Prince, R. C., Baker, A. J. M., Raskin, I., and Pickering, I. J. (1999). Zinc ligands in the metal hyperaccumulator Thlaspi caerulescens as determined using X-ray absorption spectroscopy. Environ. Sci. Technol. 33, 713-717. doi: $10.1021 /$ es $980825 \mathrm{x}$

Salt, D. E., Prince, R. C., Pickering, I. J., and Raskin, I. (1995). Mechanisms of cadmium mobility and accumulation in indian mustard. Plant Physiol. 109, 1427-1433

Sarret, G., Pilon Smits, E. A. H., Castillo Michel, H., Isaure, M. P., Zhao, F. J., and Tappero, R. (2013). Use of synchrotron-based techniques to elucidate metal uptake and metabolism in plants. Adv. Agron. 119, 1-82. doi: 10.1016/B978-012-407247-3.00001-9

Sasaki, A., Yamaji, N., Xia, J., and Ma, J. F. (2011). OsYSL6 Is involved in the detoxification of excess manganese in rice. Plant Physiol. 157, 1832-1840. doi: 10.1104/pp.111.186031

Sattelmacher, B. (2001). The apoplast and its significance for plant mineral nutrition. New Phytol. 149, 167-192. doi: 10.1046/j.1469-8137.2001.00034.x

Schaumlöffel, D., Ouerdane, L., Bouyssiere, B., and Eobin, R. (2003). Speciation analysis of nickel in the latex of a hyperaccumulating tree Sebertia acuminate by HPLC and CZE with ICP MS and electrospray MS-MS detection. J. Anal. At. Spectrom. 18, 120-127. doi: 10.1039/b209819a

Schmidke, I., Krüger, C., Frömmichen, R., Scholz, G., and Stephan, U. W. (1999) Phloem loading and transport characteristics of iron in interaction with plantendogenous ligands in castor bean seedlings. Physiol. Plant. 106, 82-89. doi: 10.1034/j.1399-3054.1999.106112.x

Schmidke, I., and Stephan, U. W. (1995). Transport of metal micronutrients in the phloem of castor bean (Ricinus communis) seedlings. Physiol. Plant. 95, 147-153. doi: 10.1111/j.1399-3054.1995.tb00821.x

Schmidt, H., Böttcher, C., Trampczynska, A., and Schuler, S. C. (2011). Use of recombinantly produced ${ }^{15} \mathrm{~N}_{3}$-labelled nicotianamine for fast and sensitive stable isotope dilution ultra-performance liquid chromatography/electrospray ionization time-of-flight mass spectrometry. Anal. Bioanal. Chem. 399, 1355-1361. doi: 10.1007/s00216-010-4436-7

Schuler, M., Rellán-Álvarez, R., Fink-Straube, C., Abadía, J., and Bauer, P. (2012). Nicotianamine functions in the phloem-based transport of iron to sink organs, in pollen development and in pollen tube growth in Arabidopsis. Plant Cell 24, 2380-2400. doi: 10.1105/tpc.112.099077

Shelp, B. J. (1987). The composition of phloem exudate and xylem sap from Broccoli (Brassica oleracea var. italica) supplied with $\mathrm{NH}^{4+}, \mathrm{NO}_{3}^{-}$or $\mathrm{NH}_{4} \mathrm{NO}_{3}$. J. Exp. Bot. 38, 1619-1636. doi: 10.1093/jxb/38.10.1619

Silva, A. M., Kong, X., Parkin, M. C., Cammack, R., and Hider, R. C. (2009). Iron(III) citrate speciation in aqueous solution. Dalton Trans. 40, 8616-8625. doi: 10.1039/b910970f

Sinclair, S. A., and Krämer, U. (2012). The zinc homeostasis network of land plants. Biochim. Biophys. Acta 1823, 1553-1567. doi: 10.1016/j.bbamcr.2012.05.016 
Singh, U. M., Sareen, P., Sengar, R. S., and Kumar, A. (2013). Plant ionomics: a newer approach to study mineral transport and its regulation. Acta Physiol. Plant. 35, 2641-2653. doi: 10.1007/s11738-013-1316-8

Song, J., Yang, Y. Q., Zhu, S. H., Chen, G. C., Yuan, X. F., Liu, T. T., et al. (2013). Spatial distribution and speciation of copper in root tips of cucumber revealed by $\mu$-XRF and $\mu$-XANES. Biol. Plant. 57, 581-586. doi: 10.1007/s10535-0130317-1

Sperotto, R. A., Ricachenevsky, F. K., Waldow Vde A., and Fett, J. P. (2012). Iron biofortification in rice: it's a long way to the top. Plant. Sci. 190, 24-39. doi: 10.1016/j.plantsci.2012.03.004

Suzuki, M., Takahashi, M., Tsukamoto, T., Watanabe, S., Matsuhashi, S., Yazaki, J., et al. (2006). Biosynthesis and secretion of mugineic acid family phytosiderophores in zinc-deficient barley. Plant J. 48, 85-97. doi: 10.1111/j.1365313X.2006.02853.x

Suzuki, M., Tsukamoto, T., Inoue, H., Watanabe, S., Matsuhashi, S., Takahashi, M., et al. (2008). Deoxymugineic acid increases $\mathrm{Zn}$ translocation in $\mathrm{Zn}$-deficient rice plants. Plant Mol. Biol. 66, 609-617. doi: 10.1007/s11103-008-9292-x

Takahashi, M., Terada, Y., Nakai, I., Nakanishi, H., Yoshimura, E., Mori, S., et al. (2003). Role of nicotianamine in the intracellular delivery of metals and plant reproductive development. Plant Cell 15, 1263-1280. doi: 10.1105/tpc.010256

Tanaka, K., Fujimaki, S., Fujiwara, T., Yoneyama, T., and Hayashi, H. (2007). Quantitative estimation of the contribution of the phloem in cadmium transport to grains in rice plants (Oryza sativa L.). Soil Sci. Plant Nutr. 53, 72-77. doi: 10.1111/j.1747-0765.2007.00116.x

Tehseen, M., Cairns, N., Sherson, S., and Cobbett, C. S. (2010). Metallochaperonelike genes in Arabidopsis thaliana. Metallomics 2, 556-564. doi: $10.1039 / \mathrm{c} 003484 \mathrm{c}$

Terzano, R., Mimmo, T., Vekemans, B., Vincze, L., Falkenberg, G., Tomasi, N., et al. (2013). Iron $(\mathrm{Fe})$ speciation in xylem sap by XANES at a high brilliant synchrotron X-ray source: opportunities and limitations. Anal. Bioanal. Chem. 405, 5411-5419. doi: 10.1007/s00216-013-6959-1

Thimm, O., Essigmann, B., Kloska, S., Altmann, T., and Buckhout, T. J. (2001). Response of Arabidopsis to iron deficiency stress as revealed by microarray analysis. Plant Physiol. 127, 1030-1043. doi: 10.1104/pp.010191

Thomine, S., and Vert, G. (2013). Iron transport in plants: better be safe than sorry. Curr. Opin. Plant Biol. 16, 322-327. doi: 10.1016/j.pbi.2013.01.003

Tian, S., Lu, L., Yang, X., Webb, S. M., Du, Y., and Brown, P. A. (2010). Spatial imaging and speciation of lead in the accumulator plant Sedum alfredii by microscopically focused synchrotron x-ray investigation. Environ. Sci. Technol. 44, 5920-5926. doi: 10.1021/es903921t

Tiffin, L. O. (1966). Iron translocation. I. Plant culture exudate sampling ironcitrate analysis. Plant Physiol. 41, 510-514. doi: 10.1104/pp.41.3.510

Trampczynska, A., Küpper, H., Meyer-Klaucke, W., Schmidt, H., and Clemens, S. (2010). Nicotianamine forms complexes with $\mathrm{Zn}(\mathrm{II})$ in vivo. Metallomics 2 , 57-66. doi: 10.1039/b913299f

Tsednee, M., Mak, Y. W., Chen, Y. R., and Yeh, K. C. (2012). Sensitive LC-ESIQ-TOF-MS method reveals novel phytosiderophores and phytosiderophoreiron complexes in barley. New Phytol. 195, 951-961. doi: 10.1111/j.14698137.2012.04206.x

Tsukamoto, T., Nakanishi, H., Kiyomiya, S., Watanabe, S., Matsuhashi, S., Nishizawa, N. K., et al. (2006). ${ }^{52} \mathrm{Mn}$ translocation in barley monitored using a positron-emitting tracer imaging system. Soil Sci. Plant Nutr. 52, 717-725. doi: 10.1111/j.1747-0765.2006.00096.x

Tsukamoto, T., Nakanishi, H., Uchida, H., Watanabe, S., Matsuhashi, S., Mori, S. et al. (2009). ${ }^{52} \mathrm{Fe}$ translocation in barley as monitored by a positron- emitting tracer imaging system (PETIS): evidence for the direct translocation of Fe from roots to young leaves via phloem. Plant Cell Physiol. 50, 48-57. doi: $10.1093 / \mathrm{pcp} / \mathrm{pcn} 192$

Ueno, D., Iwashita, T., Zhao, F. J., and Ma, J. F. (2008). Characterization of $\mathrm{Cd}$ translocation and identification of the Cd form in xylem sap of the Cdhyperaccumulator Arabidopsis halleri. Plant Cell Physiol. 49, 540-548. doi: $10.1093 / \mathrm{pcp} / \mathrm{pcn} 026$

Uraguchi, S., Mori, S., Kuramata, M., Kawasaki, A., Arao, T., and Ishikawa, S. (2009). Root-to-shoot Cd translocation via the xylem is the major process determining shoot and grain cadmium accumulation in rice. J. Exp. Bot. 60 , 2677-2688. doi: 10.1093/jxb/erp119

Vacchina, V., Mari, S., Czernic, P., Marques, L., Pianelli, K., Schaumloffel, D., et al (2003). Speciation of nickel in a hyperaccumulating plant by high-performance liquid chromatography-inductively coupled plasma mass spectrometry and electrospray MS/MS assisted by cloning using yeast complementation. Anal. Chem. 75, 2740-2745. doi: 10.1021/ac020704m

van Belleghem, F., Cuypers, A., Semane, B., Smeets, K., Vangronsveld, J., d'Haen, J., et al. (2007). Subcellular localization of cadmium in roots and leaves of Arabidopsis thaliana. New Phytol. 173, 495-508. doi: 10.1111/j.14698137.2006.01940.x

van Goor, B. J., and Wiersma, D. (1976). Chemical forms of manganese and zinc in phloem exudate. Physiol. Plant. 36, 213-216. doi: 10.1111/j.13993054.1976.tb03938.x

Vilaine, F., Palauqui, J. C., Amselem, J., Kusiak, C., Lemoine, R., and Dinant, S. (2003). Towards deciphering phloem: a transcriptome analysis of the phloem of Apium graveolens. Plant J. 36, 67-81. doi: 10.1046/j.1365-313X.2003.01855.x

Vogel-Mikus, K., Arcon, I., and Kodre, A. (2010). Complexation of cadmium in seeds and vegetative tissues of the cadmium hyperaccumulator Thlaspi praecox as studied by X-ray absorption spectroscopy. Plant Soil 331, 439-451. doi: 10.1007/s11104-009-0264-y

von Blanckenburg, F., von Wirén, N., Guelke, M., Weiss, D. J., and Bullen, T. D. (2009). Fractionation of metal stable isotopes by higher plants. Elements 5, 375-380. doi: 10.2113/gselements.5.6.375

von Wirén, N., Khodr, H., and Hider, R. C. (2000). Hydroxylated phytosiderophore species possess an enhanced chelate stability and affinity for iron(III). Plant Physiol. 124, 1149-1157. doi: 10.1104/pp.124.3.1149

von Wirén, N., Klair, S., Bansal, S., Briat, J. F., Khodr, H., Shioiri, T., et al. (1999). Nicotianamine chelates both Fe-III and Fe-II. Implications for metal transport in plants. Plant Physiol. 119, 1107-1114. doi: 10.1104/pp.119.3.1107

Wada, Y., Yamaguchi, I., Takahashi, M., Nakanishi, H., Mori, S., and Nishizawa, N. K. (2007). Highly sensitive quantitative analysis of nicotianamine using LC/ESITOF-MS with an internal standard. Biosci. Biotechnol. Biochem. 71, 435-441. doi: $10.1271 /$ bbb. 60496

Watanabe, T., and Osaki, M. (2001). Influence of aluminum and phosphorus on growth and xylem sap composition in Melastoma malabathricum L. Plant Soil 237, 63-70. doi: 10.1023/A:1013395814958

Waters, B. M., and Sankaran, R. P. (2011). Moving micronutrients from the soil to the seeds: genes and physiological processes from a biofortification perspective Plant Sci. 180, 562-574. doi: 10.1016/j.plantsci.2010.12.003

Watmough, S. A., Hutchinson, T. C., and Evans, R. D. (1999). The distribution of ${ }^{67} \mathrm{Zn}$ and ${ }^{207} \mathrm{~Pb}$ applied to white spruce foliage at ambient concentrations under different pH regimes. Environ. Exp. Bot. 41, 83-92. doi: 10.1016/S00988472(98)00056-2

Weber, G., von Wirén, N., and Hayen, H. (2006). Analysis of iron(II)/iron(III) phytosiderophore complexes by nano-electrospray ionization Fourier transform ion cyclotron resonance mass spectrometry. Rapid Commun. Mass Spectrom. 20, 973-980. doi: 10.1002/rcm.2402

Wei, Z. G., Wong, J. W., Hong, F., Zhao, H. Y., Li, H. X., and Hu, F. (2007a). Determination of inorganic and organic anions in xylem saps of two contrasting oilseed rape (Brassica juncea L.) varieties: roles of anions in long-distance transport of cadmium. Microchem. J. 86, 53-59. doi: 10.1016/j.microc.2006. 10.003

Wei, Z. G., Wong, J. W., Zhao, H. Y., Zhang, H. J., Li, H. X., and Hu, F. (2007b) Separation and determination of heavy metals associated with low molecular weight chelators in xylem xaps of Indian Mustard (Brassica juncea) by size exclusion chromatography and atomic absorption spectrometry. Biol. Trace Elem. Res. 118, 146-158. doi: 10.1007/s12011-007-0022-Z

White, M. C., Decker, A. M., and Chaney, R. L. (1981). Metal complexation in xylem fluid. Plant Physiol. 67, 292-300. doi: 10.1104/pp.67.2.292

Wiersma, D., and van Goor, B. J. (1979). Chemical forms of nickel and cobalt in phloem of Ricinus communis. Physiol. Plant. 45, 440-442. doi: 10.1111/j.13993054.1979.tb02610.x

Wirth, J., Poletti, S., Aeschlimann, B., Yakandawala, N., Drosse, B., Osorio, S., et al. (2009). Rice endosperm iron biofortification by targeted and synergistic action of nicotianamine synthase and ferritin. Plant Biotechnol. J. 7, 631-644. doi: 10.1111/j.1467-7652.2009.00430.x

Wood, B. A., and Feldmann, J. (2012). Quantification of phytochelatins and their metal(loid) complexes: critical assessment of current. Anal. Bioanal. Chem. 402, 3299-3309. doi: 10.1007/s00216-011-5649-0

Wu, B., Chen, Y. X., and Becker, J. S. (2009). Study of essential element accumulation in the leaves of a Cu-tolerant plant Elsholtzia splendens after $\mathrm{Cu}$ treatment by imaging laser ablation inductively coupled plasma mass spectrometry (LAICP-MS). Anal. Chimica Acta 633, 165-172. doi: 10.1016/j.aca.2008.11.052 
Wycisk, K., Kim, E. J., Schroeder, J. I., and Krämer, U. (2004). Enhancing the first enzymatic step in the histidine biosynthesis pathway increases the free histidine pool and nickel tolerance in Arabidopsis thaliana. FEBS Lett. 578, 128-134. doi: 10.1016/j.febslet.2004.10.086

Xuan, Y., Scheuermann, E. B., Meda, A. R., Hayen, H., von Wirén, N., and Weber, G. (2006). Separation and identification of phytosiderophores and their metal complexes in plants by zwitterionic hydrophilic interaction liquid chromatography coupled to electrospray ionization mass spectrometry. J. Chromatogr. A 1136, 73-81 doi: 10.1016/j.chroma.2006.09.060

Xuan, Y., Scheuermann, E. B., Meda, A. R., Jacob, P., von Wirén, N., and Weber, G. (2007). CE of phytosiderophores and related metal species in plants. Electrophoresis 28, 3507-3519. doi: 10.1002/elps.200700117

Yamaguchi, N., Ishikawa, S., Abe, T., Baba, K., Arao, T., and Terada, Y. (2012). Role of the node in controlling traffic of cadmium, zinc, and manganese in rice. J. Exp. Bot. 63, 2729-2737. doi: 10.1093/jxb/err455

Ye, W. L., Wood, B. A., Stroud, J. L., Andralojc, P. J., Raab, A., McGrath, S. P., et al. (2010). Arsenic speciation in phloem and xylem exudates of castor bean. Plant Physiol. 54, 1505-1513. doi: 10.1104/pp.110.163261

Yokosho, K., Yamaji, N., Ueno, D., Mitani, N., and Ma, J. F. (2009). OsFRDL1 is a citrate transporter required for efficient translocation of iron in rice. Plant Physiol. 149, 297-305. doi: 10.1104/pp.108.128132

Yoneyama, T. Gosho, T. Kato, M., Goto, S., and Hayashi, H. (2010). Xylem and phloem transport of $\mathrm{Cd}, \mathrm{Zn}$ and $\mathrm{Fe}$ into the grains of rice plants (Oryza sativa L.) grown in continuously flooded Cd-contaminated soil. Soil Sci. Plant Nutr. 56, 445-453. doi: 10.1111/j.1747-0765.2010.00481.x

Yoshimura, E., Sakaguchi, T., Nakanishi, H., Nishizawa, N. K., Nakai, I., and Mori, S. (2000). Characterization of the chemical state of iron in the leaves of wild-type tomato and of a nicotianamine-free mutant chloronerva by X-ray
Absorption Near-edge Structure (XANES). Phytochem. Anal. 11, 160-162. doi: 10.1002/(SICI)1099-1565(200005/06)11:3<160::AID-PCA500>3.0.CO;2-C

Yruela, I. (2009). Copper in plants: acquisition, transport and interactions. Funct. Plant Biol. 36, 409-430. doi: 10.1071/FP08288

Yun, W., Pratt, S. T., Miller, R. M., Cai, Z., Hunter, D. B., Jarstfer, A. G., et al. (1998). $\mathrm{X}$-ray imaging and microspectroscopy of plants and fungi. J. Synchrotron Radiat. 5, 1390-1395. doi: 10.1107/S0909049598007225

Zhang, C., Yu, X., Ayre, B. G., and Turgeon, R. (2012). The origin and composition of curcubit "phloem" exudate. Plant Physiol. 158, 1873-1882. doi: 10.1104/pp.112.194431

Conflict of Interest Statement: The authors declare that the research was conducted in the absence of any commercial or financial relationships that could be construed as a potential conflict of interest.

Received: 22 January 2014; accepted: 04 March 2014; published online: 25 March 2014 Citation: Álvarez-Fernández A, Díaz-Benito P, Abadía A, López-Millán A-F and Abadía J (2014) Metal species involved in long distance metal transport in plants. Front. Plant Sci. 5:105. doi: 10.3389/fpls.2014.00105

This article was submitted to Plant Nutrition, a section of the journal Frontiers in Plant Science.

Copyright (C) 2014 Álvarez-Fernández, Díaz-Benito, Abadía, López-Millán and Abadia. This is an open-access article distributed under the terms of the Creative Commons Attribution License (CC BY). The use, distribution or reproduction in other forums is permitted, provided the original author(s) or licensor are credited and that the original publication in this journal is cited, in accordance with accepted academic practice. No use, distribution or reproduction is permitted which does not comply with these terms. 